\title{
OPEN Experimental study and modelling of asphaltene deposition on metal surfaces with superhydrophobic and low sliding angle inner coatings
}

\author{
Mohammad Haji-Savameri ${ }^{1}$, Saeid Norouzi-Apourvari ${ }^{1 凶}$, Ahmad Irannejad ${ }^{2}$, \\ Abdolhossein Hemmati-Sarapardeh ${ }^{1,3,4 凶}$, Mahin Schaffie ${ }^{1}$ \& Amir Mosavi ${ }^{i 凶}$
}

Inner coatings have emerged as a novel technique to prevent the deposition of paraffin, wax, scale, and corrosion of pipelines during oil production and transport. Few studies addressed this technique for preventing asphaltene deposition. In this study, two superhydrophobic inner coatings, including polytetrafluoroethylene (PTFE) coating and nanosilica coating, were fabricated on metal surfaces and the asphaltene deposition on these coated surfaces was examined. A model oil solution was prepared using asphaltene and heptol and the effect of static and dynamic flow states on the amount of asphaltene deposition on uncoated electrodes, PTFE coated electrodes, and nanosilica coated electrodes were investigated. The results showed that the PTFE coating is more effective in reducing asphaltene deposition than nanosilica coating. The PTFE coating could reduce $56 \%$ of the deposition in a static state and more than $70 \%$ in a dynamic state at an asphaltene concentration of $2000 \mathrm{ppm}$. For PTFE coating in a dynamic state, the deposition rate is negligible in long times. In addition, it was found that the type of flow state affects the asphaltene deposition kinetics. The results demonstrate that, in the static state, the nth-order kinetics model, and in the dynamic state, the double exponential models are in best agreement with the experimental data.

One of the major challenges in the production and processing of crude oil is the deposition of heavy hydrocarbons including asphaltenes and waxes ${ }^{1}$ on the surface of well tubing, pipeline, and refining catalysts. Asphaltene molecules, as the heaviest and most polar components of crude oil ${ }^{2}$, are suspended in oil by resins under favorable conditions. Pressure, temperature, oil composition, the amount and type of injecting gas for enhanced oil recover $y^{3,4}$, the amount of gas associated with oil, the type of flow in the porous media, and the characteristics of the fluid-containing pipes can be considered as effective factors on asphaltene precipitation and deposition ${ }^{5}$. Pressure is one of the most important parameters in the asphaltene deposition process, and other factors fall into the second order. The highest amount of asphaltene deposition occurs near the wellbore, where the highest pressure drop occurs with increasing production $^{6-8}$. Reservoir pressure maintenance is probably the most effective technique to avoid asphaltene deposition in wells ${ }^{9,10}$. In oil production process, which is accompanied by a simultaneous decrease in pressure and temperature, asphaltene molecules precipitate and form sludge-like and highly adherent masses ${ }^{11}$. It is worth mentioning that the term deposition is commonly used to describe the process of precipitation ${ }^{12}$. Clarification of the differences between these two terms is important. The precipitation may be described as the formation of a solid phase from a liquid solution, while deposition can be defined as the formation and growth of a precipitated solid layer on the surface. Precipitation could be a prelude to deposition, but it does not necessarily guarantee deposition formation ${ }^{13,14}$. Asphaltene deposition could affect all components of the production system from the reservoir to the wellbore and up to the surface facility and pipelines. In porous media, the asphaltene deposition could plug the pore throats and alter the rock wettability ${ }^{15}$. The main mechanism(s) of deposition of asphaltene particles in porous media and resulting permeability damage have been investigated in the literature. In one of these studies, "surface deposition" was identified as the main

${ }^{1}$ Department of Petroleum Engineering, Shahid Bahonar University of Kerman, Kerman, Iran. ${ }^{2}$ Department of Materials Engineering and Metallurgy, Shahid Bahonar University of Kerman, Kerman, Iran. ${ }^{3}$ Institute of Research and Development, Duy Tan University, Da Nang 550000, Vietnam. ${ }^{4}$ Faculty of Environment and Chemical Engineering, Duy Tan University, Da Nang 550000, Vietnam. ${ }^{5}$ John Von Neumann Faculty of Informatics, Obuda University, Budapest 1034, Hungary. ${ }^{\boxplus}$ email: snorouzi@uk.ac.ir; hemmati@uk.ac.ir; amir.mosavi@ kvk.uni-obuda.hu 
mechanism in reducing the permeability of porous media ${ }^{16}$. It gradually blocks the wells and other transmission pipes and could also cause obstruction and failure of valves, separators, and other equipment it passes through. In refineries and petrochemical factories, even a small amount of asphaltene drastically reduces the efficiency of catalysts and other additives ${ }^{17}$.

The most costly and challenging problem related to depositions during crude oil production and processing cycle from reservoirs to petrochemicals and refineries occurs when access to the deposits is limited. The mitigation of deposition in the wellbore, for instance, requires chemical treatment which is costly and not an environmentally friendly method. Therefore, the deposition in the wellbore should be avoided as much as possible ${ }^{18}$. In tackling the challenge of asphaltene deposition in the industry, two main strategies are usually chosen, including deposition prevention and treatment and removal of deposition. The methods commonly used for deposition removal are generally divided into three categories, namely mechanical, chemical, and thermal methods ${ }^{19}$, among which the thermal methods are less efficient. Oil companies usually use chemicals, such as solvent (xylene) injection or acid injection using coil tubing, which can only remove depositions and are not capable to prevent the depositions buildup. In addition, the frequent need for solvent injections over a period of approximately 1 year (and in some cases months) will result in increased costs and repeated stoppages ${ }^{20}$. Therefore, prevention is always the preferred treatment if it is viable. In fact, chemical injection, and the use of mechanical and thermal methods, are normally introduced when the production process cannot be modified to prevent deposition ${ }^{18}$. The application of special coatings on the inner surfaces of pipes is another interesting approach to prevent or minimize deposition.

In the petroleum industry, the application of various coatings to prevent and reduce the deposition of solids such as asphaltene, scale, and wax, under flow conditions in wells and pipelines, has been investigated in various studies $^{21-29}$. Coatings have been used for many years to prevent the deposition of paraffin, wax, scale, and corrosion of pipelines. Although their effectiveness in dealing with these cases has been approved, less effort has been devoted to asphaltene deposition. As mentioned earlier, asphaltene is the heaviest and most polar component of crude oil $^{2}$, and water always competes with asphaltene molecules in adhering to different surfaces ${ }^{30}$. Therefore, the application of hydrophobic coatings could prevent the deposition of minerals and greatly reduce corrosion and asphaltene deposition.

Recent studies have tried to apply various coatings to prevent asphaltene deposition. Many of these methods are multi-stage and do not produce a surface with superhydrophobic properties ${ }^{24}$. More sophisticated coatings were also applied on different surfaces. The methods of fabrication and application of these coatings are very complex and require special equipment ${ }^{21,27}$. In addition, none of these coatings have superhydrophobic properties. The low sticking tendency of polytetrafluoroethylene (PTFE) polymers makes them desirable coating materials for controlling scales if applied appropriately. It should also be noted that the PTFE alone may have low surface energy and can create a hydrophobic surface, but what is important for reducing asphaltene deposition and other sediments is a low sliding angle, which can be achieved by creating the proper roughness on the surface.

The objective of this study is twofold. First, the effect of engineered superhydrophobic surfaces on reducing asphaltene deposition is examined, and later, the kinetic of asphaltene deposition on these coated surfaces is modeled. Asphaltene extracted from a crude oil sample and dissolved in heptol is subjected to an electric field for simulating the deposition process on coated and uncoated metal surfaces. Both PTFE-coated electrodes and nanosilica coated electrodes are examined. Different flow states and asphaltene concentrations of 2000, 1000, and $250 \mathrm{ppm}$ are considered. These investigations could help us to better understand the factors affecting the kinetics of asphaltene deposition on coated and uncoated surfaces, which are necessary for choosing the optimal prohibitive measures in oil fields. It is necessary to mention that, the coatings fabricated in this study are suitable as inner coatings.

\section{Materials and experimental procedures}

Preparation of electrodes. The electrodes used in this study are made of low-carbon steels with 0.15$0.30 \%$ carbon. Metal blades were cut from a sheet with a thickness of $0.1 \mathrm{~cm}$ in dimensions of $2.5 \mathrm{~cm} \times 10 \mathrm{~cm}$. In this study, two types of electrodes, including PTFE and nanosilica coated electrodes, were used to examine the asphaltene deposition on superhydrophobic surfaces. PTFE coating includes a primer and an overcoat layer. In order to produce superhydrophobic PTFE coating with hierarchical structure and low surface energy, glass beads microparticles with an average size of 82 microns were used in the primer layer. This coating was applied on the metal surfaces by spraying process at a pressure range of 50-100 Psi. For the second type of coating, the superhydrophobic nanosilica coating was applied on the metal surfaces by a one-step electrodeposition process of a sol-gel, which contained tetraethoxysilane (TEOS) (purity $\geq 98.5 \%$ ) and dodecyltrimethoxysilane (DTMS) (purity $>93 \%$ ) as mixed sol-gel precursors. The precursor solution contains $1 \mathrm{ml}$ TEOS, $1 \mathrm{ml}$ DTMS, $10 \mathrm{ml}$ potassium nitrate, and $40 \mathrm{ml}$ ethanol. The solution $\mathrm{pH}$ was adjusted to 4 by hydrochloric acid. This solution was pre-hydrolyzed for $12 \mathrm{~h}$ at room temperature via strong stirring. The electrodeposition process was then performed on the surface of the metal blades. The wetting properties of the coated and uncoated surfaces are obtained by measuring the contact angle (CA) and sliding angle (SA). The CA was measured on several different samples of uncoated surfaces. The uncoated surfaces had CA of $57^{\circ}-97^{\circ}$ and SA more than $90^{\circ}$, and therefore had neutral and somewhat hydrophilic wetting properties (the CA reported in this study is the average of five measurements at different points on the coated and uncoated surfaces). This suggests that asphaltene deposition tests have been performed on uncoated surfaces with neutral to hydrophilic wetting properties. While both PTFE coating and nanosilica coating produced superhydrophobic surfaces, the PTFE coating reached a CA of $152 \pm 0.220^{\circ}$ and $\mathrm{SA}$ of $3 \pm 0.376^{\circ}$ and a CA of $166 \pm 0.481^{\circ}$ and SA of nearly zero were obtained for nanosilica coating. It is worth noting that, what is important for the reproduction of PTFE coating processes in the spray method is the correct selection of micro particle size distribution, control of the nozzle distance from the surface 


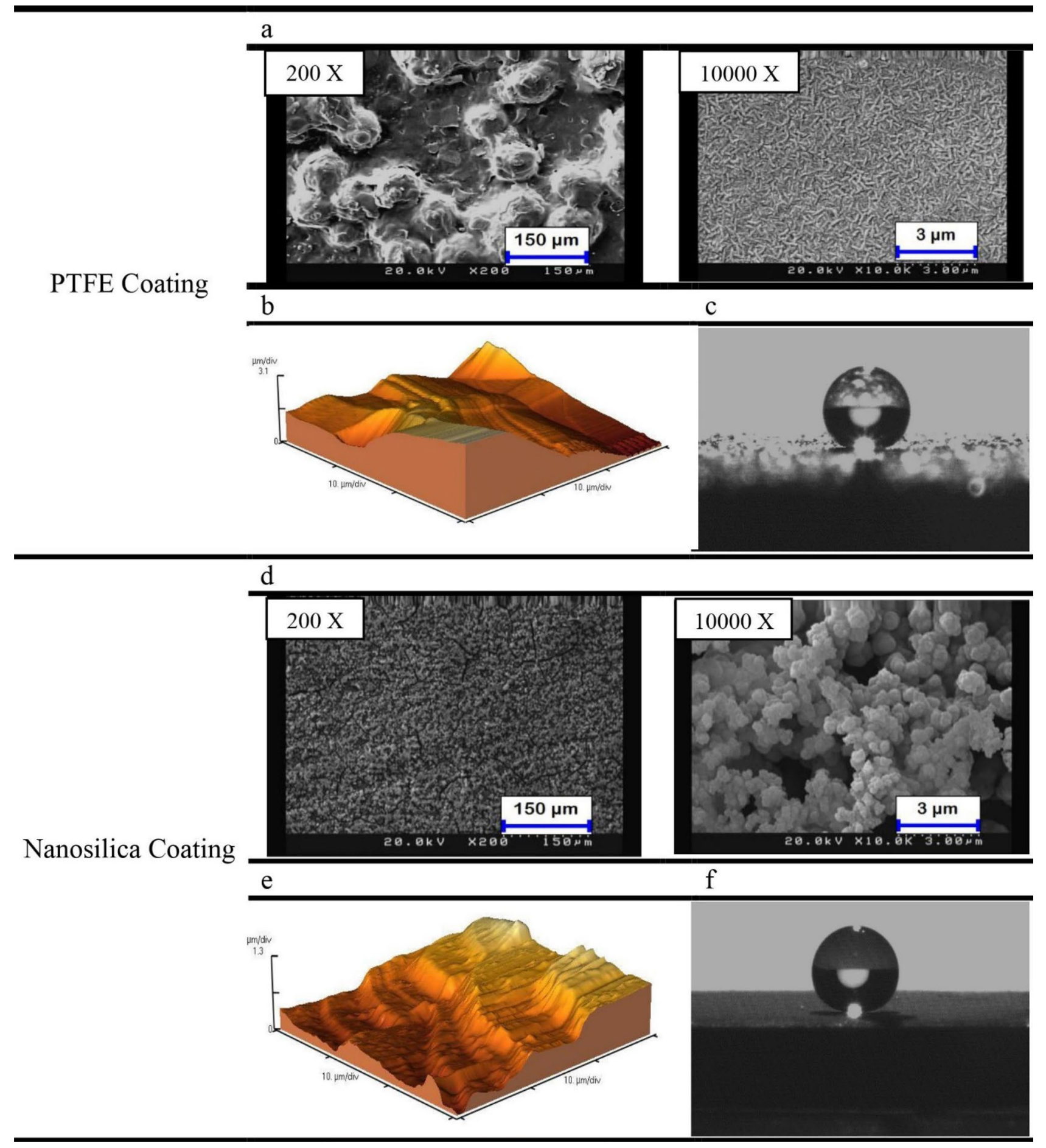

Figure 1. (a,d) SEM images and $(\mathbf{b}, \mathbf{e})$ images of $3 \mathrm{D}$ AFM $\left(10 \times 10 \mu \mathrm{m}^{2}\right)$ and $(\mathbf{c}, \mathbf{f})$ WCA images for PTFE and nanosilica coatings.

and the injection pressure. In the reproduction of nanosilica coating by electrodiposition method, precise regulation of current density and precise control of sol-gel solution $\mathrm{pH}$ are important. In our study, many samples were made by each method and for all of them the wettability properties were measured and compared and in all cases the results were very consistent. The surface roughness plays a major role in wettability. An atomic force microscope (AFM) (CP II, Veeco) was used to measure the roughness of two representative coated surfaces. The scan range was $10 \times 10 \mu \mathrm{m}^{2}$. Figure 1 shows surface morphology images (Fig. 1a,d), 3D AFM images (Fig. 1b,e), and water contact angle (WCA) images (Fig. 1c,f) of PTFE and nanosilica coatings. The procedure of the current study is shown in Fig. 2. 


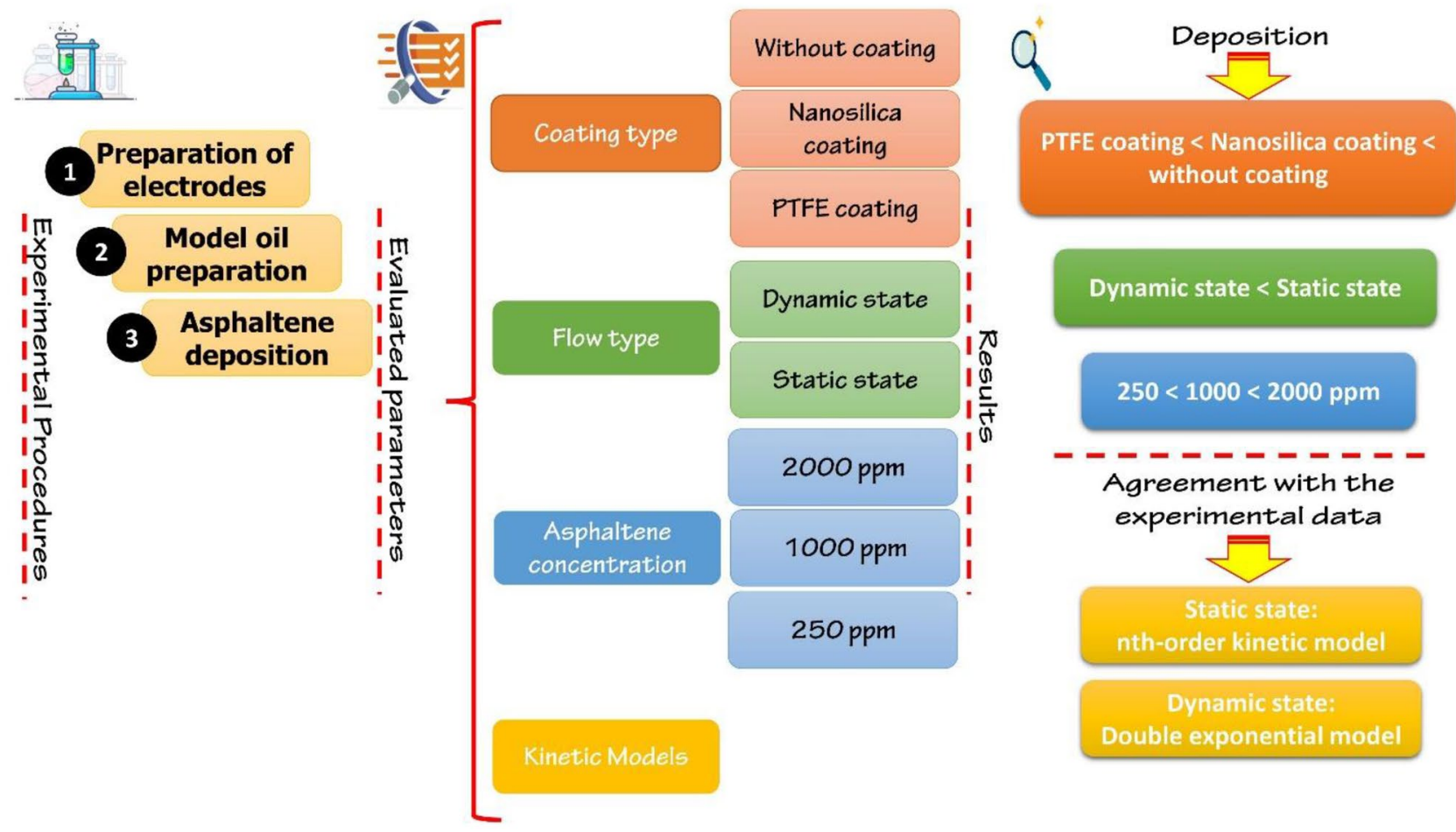

Figure 2. The procedure of experiments conducted in this study.

Model oil preparation. Toluene and normal heptane were purchased with a purity of $99 \%$. Crude oil samples were obtained from one of the oil reservoirs located in the southwest of Iran. The asphaltene was extracted from a crude oil sample according to the IP-143 standard method. Additional information on the composition of asphaltene extracted from crude oil based on H/C ratio, FTIR aromatic index, the heteroatoms content, the number of aliphatic chains and the XRD aromatic index are available in the literature ${ }^{31}$. The dried asphaltene powder was first dissolved in toluene by sonication at $40 \mathrm{kHz}$ and then normal heptane was gradually added to the solution on a magnetic stirrer. The mixture was sonicated again for 5 min and was kept static for $24 \mathrm{~h}$ to achieve equilibrium. In this study, three different levels of asphaltene concentrations including $2000 \mathrm{ppm}$, $1000 \mathrm{ppm}$, and $250 \mathrm{ppm}$ with toluene/n-heptan ratio of 1.6/38.4 (4\% toluene concentration) were used to investigate the electrodeposition of asphaltene on coated and uncoated surfaces. These concentration values are initial concentrations. These values have been selected based on previous studies ${ }^{32}$. It should be noted that this mixture was prepared at ambient pressure and temperature. Although asphaltene particles in real crude oil show a neutral charge ${ }^{33-35}$, their charge in heptol solution depends on the concentration of toluene in the solution. It is worth mentioning that the electrodeposition process here was only used to simulate unstable asphaltene deposition.

Asphaltene deposition process on surfaces of the electrodes. Given the mycelial structure of asphaltenes and the presence of heteroatoms and metal elements such as nickel and vanadium in the constituent structure of asphaltene molecules and functional groups, it can be assumed that these compounds have a charge $^{36}$. Numerous experiments have shown that asphaltenes in the electric field are directly affected by the force of the electric field ${ }^{37,38}$. In one comprehensive study, conducted by Hosseini et al. ${ }^{39}$, the effect of electric fields with different strengths on three different asphaltene samples was investigated. The main purpose of this study was to determine the amount of aggregation rate and aggregation size of asphaltene particles in the electrostatic field which was done using the visual inspection method. Based on the results obtained, the higher the aggregation rate the aggregation size of asphaltene particles in the electrostatic field may cause faster deposition. According to studies conducted in the literature, in this study, an electrical deposition cell was used to simulate the asphaltene deposition on coated and uncoated surfaces. The electrical deposition cell used in this study contains $40 \mathrm{ml}$ of solution in a static state, and in dynamic state experiments, a shear rate was applied using a stirring magnet in $50 \mathrm{ml}$ of solution. Figure 3 shows a schematic of the device used to perform the asphaltene deposition process on the coated and uncoated electrodes. Two metal electrodes are held in parallel by a removable plastic cap. A high voltage power supply device (Oltronix LS 529R) was used to convert alternating current (AC) to direct current (DC) and create an electric field between two electrodes. During the asphaltene deposition process, an uncoated blade, which is fixed in all experiments, plays the role of the anode, and the coated and uncoated blades play the role of the cathode. In order to measure the amount of asphaltene deposition, all blades were numbered first and the weight of each was measured and recorded using the analytical weighing scale with $\pm 0.0001 \mathrm{~g}$ accuracy. The weight of the electrodes used in this study was $30 \mathrm{~g}$ on average. At the end of each test, after removing the blades from the solution, they were placed at room temperature to be dried completely. After drying, a uniform blackish-brown layer of asphaltene deposit was being observed on the surface of 


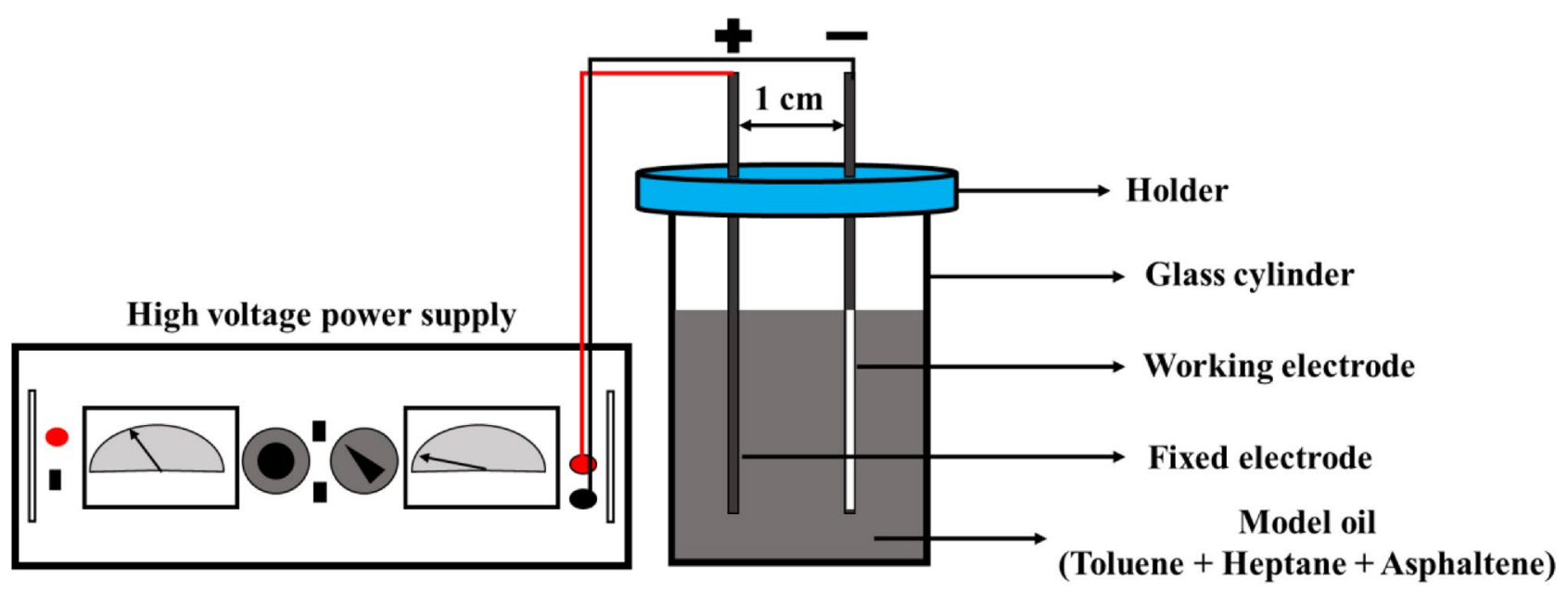

Figure 3. A schematic of the electrodeposition system.

the blade. The weight of these blades was measured and recorded at the end of the experiment and after drying at room temperature. The difference between the weight of the blades at the end of the experiment (blades containing asphaltene deposition) and their weight at the beginning of the experiment (clean blades) indicates the amount of asphaltene deposition. The strength of the electric field was determined based on experiments performed on the uncoated sample. Based on the obtained results, the amount of asphaltene deposition on uncoated electrodes at an electric field strength of $2 \mathrm{kV} / \mathrm{cm}$ reached its maximum ${ }^{32}$. For this reason, in this study, $2 \mathrm{kV} /$ $\mathrm{cm}$ electric field strength was used to maximize the amount of deposition. In order to investigate the asphaltene deposition on coated and uncoated surfaces at different concentrations and different flow states, each electrode was exposed to an electric field at 5, 10,20, 40,60, 80, 120, 180 and $300 \mathrm{~s}$, and the amount of asphaltene deposition at any time and in any situation was assessed. It should be noted that in order to measure the asphaltene deposition at any time, a new experiment was conducted. The experiments were repeated three times for each deposition condition, and the average values of these runs are reported here.

\section{Kinetic models}

In general, measuring, predicting, and understanding deposition rate in engineering sciences is very important. Some efforts ${ }^{40-43}$ have been made to model the asphaltene deposition based on deposition kinetic for selecting the optimal operating conditions and the treatment of asphaltene deposition at the field scale. All these studies were conducted for uncoated surfaces ${ }^{44,45}$.

In order to describe the results of static and dynamic experiments at different concentrations and times, the double exponential model, diffusion equation model, Elovich's equation model, nth-order kinetics and modified second-order models were used. Although these models are suitable for modeling the adsorption process, the application of these models in this study could also provide a good insight into the kinetics of the adsorption/ deposition process.

Double exponential model. This model was developed in 1993 by Wilczak and Keinath ${ }^{46}$ and is used to describe the adsorption process with respect to both chemical and mathematical perspectives. The model links the two-step mechanism of the fast and slow adsorption process ${ }^{47}$ as given in Eq. (1):

$$
Q_{t}=Q_{e}-\frac{D_{1}}{m_{a d s}} \exp \left(-K_{D 1} t\right)-\frac{D_{2}}{m_{a d s}} \exp \left(-K_{D 2} t\right)
$$

where $Q_{t}$ and $Q_{e}$, are the amount of asphaltenes at each time point of contact and the amount of asphaltene adsorbed on the surface of the electrode at equilibrium $\left(\mathrm{mg} / \mathrm{cm}^{2}\right)$, respectively. $D 1$ and $D 2$ are asphaltene fast and slow adsorption fraction $(\mathrm{mg} / \mathrm{l}), t$ is time, $K_{D 1}$ and $K_{D 2}$ are fast and slow rate constants $\left(\mathrm{min}^{-1}\right)$ and $K_{D 1}$ is larger than $K_{D 2}$. It is worth noting that the sum of the two parameters $D_{1} / m_{a d s}$ and $D_{2} / m_{a d s}$ is the physical equivalent of the calculated value of $Q_{e}$. The rate of absorption of the absorbing material in both slow and fast states is expressed by $S F$ and $R F$, respectively, and is expressed by Eqs. (2) and (3).

$$
\begin{aligned}
& S F=100\left[\frac{D_{2}}{\left(D_{1}+D_{2}\right)}\right] . \\
& R F=100\left[\frac{D_{1}}{\left(D_{1}+D_{2}\right)}\right] .
\end{aligned}
$$

Diffusion equation model. The penetration of adsorbed molecules or ions into the pores is considered in order to find the appropriate kinetic model for the porous adsorbents. In many cases, the rate of absorption of 
a sorbent is controlled by the amount of penetration into the particles ${ }^{48}$. Equation (4) was expressed by Weber and Morris for this purpose.

$$
Q_{t}=k_{p} t^{\frac{1}{2}}+I
$$

In this equation, $k_{p}$ is defined as the diffusion rate coefficient and its unit is $\left[\mathrm{mg} /\left(\mathrm{cm}^{2} \times \mathrm{min}^{0.5}\right)\right]$. This rate coefficient could be obtained from the slope of the plots $\left(Q_{t}\right.$ vs. $\left.t^{0.5}\right)$, and $I$ is the intercept.

Elovich's equation model. This equation was introduced by Zeldowitsch in 1934 for absorption based on chemical bonding mechanism ${ }^{49}$. This equation is expressed by Eqs. (5) and (6).

$$
\begin{gathered}
Q_{t}=\left(\frac{2.3}{a}\right) \log \left(\mathrm{t}+\mathrm{t}_{0}\right)-\left(\frac{2.3}{\mathrm{a}}\right) \log \left(\mathrm{t}_{0}\right), \\
t_{0}=\frac{1}{\alpha a} .
\end{gathered}
$$

In this equation, $Q_{t}$ is the amount of asphaltene adsorbed at time $t, \alpha$ is the initial adsorption value in gram and $a$ is adsorption constant.

nth-Order kinetics model. In general, direct calculation of the rate constant and order of the adsorption reaction is more appropriate than assuming the reaction order, $n$, as 1 or 2 , and therefore, using the nth-order kinetic model is much more efficient ${ }^{50}$. This model is expressed by Eq. (7).

$$
Q_{t}=Q_{e}\left\{1-\left[\frac{1}{\beta_{n}+k_{n}(n-1) t}\right]^{\frac{1}{(n-1)}}\right\},
$$

where $k_{n}$ is the rate constant and its unit depends on the reaction order $(1 / \mathrm{min})\left(\mathrm{mg} / \mathrm{cm}^{2}\right)^{1-\mathrm{n}}, \beta_{n}$ is the impurity, pre-adsorbed on the surface and is defined by Eq. (8).

$$
\beta_{n}=1 /\left(1-\theta_{0}\right)^{n-1}
$$

where $\theta_{0}$ is a dimensionless surface coverage in the pre-adsorption step and is expressed by $\left(\theta_{0}=Q_{0} / Q_{e}\right)$.

Modified second-order model. Using the nth-order kinetic equation for $n=2$, a modified second-order equation can be obtained ${ }^{50}$. This model is defined by Eq. (9).

$$
Q_{t}=Q_{e}\left[1-\frac{1}{\beta+k t}\right] \text {. }
$$

\section{Results and discussion}

In this section, the effect of two different coatings and asphaltene concentration on the amount of asphaltene deposition at different flow states are analyzed and the results are discussed. Finally, we investigate the effect of these factors on the kinetics of asphaltene deposition on electrode surfaces. Table 1 summarizes the most important results obtained in each section.

The effect of coating type on asphaltene deposition in the static state. These experiments were performed at static state and asphaltene concentration of $2000 \mathrm{ppm}$ for uncoated, PTFE coated and nanosilica coated electrodes. During these experiments, other influential parameters such as time, toluene concentration, asphaltene concentration, type of flow state, and voltage were kept constant. The parameters used in the design of the experiment are listed in Table 2. The rate of asphaltene deposition on three types of electrodes as a function of exposure time to the electric field with $2 \mathrm{kV} / \mathrm{cm}$ strength, is shown in Fig. 4 . It is necessary to mention that, each data point on the asphaltene deposition rate curve, as shown in Fig. 4, was generated from an independent test. The amounts of asphaltene deposition, in this case, are shown in Table 3.

Based on our observations, the amount of asphaltene deposition on the surface of coated electrodes is lower than that of the uncoated electrode. Although the difference is not significant, the amount of asphaltene deposition on the surface of the electrode with PTFE coating is lower than that of nanosilica. It was also observed that the asphaltene deposition on the coated surfaces has low adhesion and could be easily removed from the surface after taking it out of the oil sample solution. It is worth recalling that, the asphaltene is the most polar component of crude oil and contains large amounts of active species ${ }^{51}$. They are known as key components of surface wettability change through the interaction of its polar functional groups with polar sites on a solid surface ${ }^{52,53}$. For coating created by the electrodeposition process, the wettability of the coatings largely depends on several parameters such as electrodeposition conditions of the coating such as charge transferred, applied voltage, , the alloy type and roughness of the working electrode and the surface energy of the coating ${ }^{54}$. Lower or negative surface energy values associated with lower or negative adhesion tendencies would be a more effective system for reducing asphaltene deposition ${ }^{55}$. The use of some polymer-based coatings with suitable chemically inert properties could reduce the tendency for severe asphaltene adhesion ${ }^{55}$. The coatings used to prevent or reduce 


\begin{tabular}{|c|c|c|c|}
\hline Evaluated parameter & Constant values & \multicolumn{2}{|l|}{ Results } \\
\hline Coating type & $\begin{array}{l}\text { Ambient pressure and temperature, Asphal- } \\
\text { tene concentration } 2000 \mathrm{ppm} \text {, Electric field } \\
\text { strength } 2 \mathrm{kV} / \mathrm{cm} \text {, Static state }\end{array}$ & \multirow{5}{*}{ Asphaltene deposition } & $\begin{array}{l}\text { PTFE coating }<\text { Nanosilica coating }<\text { With- } \\
\text { out coating electrode }\end{array}$ \\
\hline Type of flow state & $\begin{array}{l}\text { Ambient pressure and temperature, Asphal- } \\
\text { tene concentration } 2000 \mathrm{ppm} \text {, Electric field } \\
\text { strength } 2 \mathrm{kV} / \mathrm{cm} \text {, End of } 300 \mathrm{~s} \text { of exposure } \\
\text { to electric filed }\end{array}$ & & $\begin{array}{l}\text { For without coating electrode and PTFE } \\
\text { coating: } \\
\text { Dynamic state }<\text { Static state }\end{array}$ \\
\hline Asphaltene concentration & $\begin{array}{l}\text { Ambient pressure and temperature, Electric } \\
\text { field strength } 2 \mathrm{kV} / \mathrm{cm} \text {, PTFE coating }\end{array}$ & & $\begin{array}{l}\text { At } 2000,1000 \text { and } 250 \mathrm{ppm}: \\
\text { Dynamic state }<\text { Static state }\end{array}$ \\
\hline \multirow[t]{2}{*}{ Coating type + Asphaltene concentration } & $\begin{array}{l}\text { Ambient pressure and temperature, Electric } \\
\text { field strength } 2 \mathrm{kV} / \mathrm{cm} \text {, End of } 300 \mathrm{~s} \text { of } \\
\text { exposure to electric filed, Static state }\end{array}$ & & $\begin{array}{l}\text { PTFE coating- } 250 \text { ppm }<\text { PTFE coat- } \\
\text { ing- } 1000 \text { ppm }<\text { PTFE coating- } 2000 \text { ppm } \\
<\text { Nanosilica coating-2000 ppm }<\text { Without } \\
\text { coating- } 2000 \text { ppm }\end{array}$ \\
\hline & $\begin{array}{l}\text { Ambient pressure and temperature, Electric } \\
\text { field strength } 2 \mathrm{kV} / \mathrm{cm} \text {, End of } 300 \mathrm{~s} \text { of } \\
\text { exposure to electric filed, Dynamic state }\end{array}$ & & $\begin{array}{l}\text { PTFE coating- } 250 \text { ppm }<\text { PTFE coat- } \\
\text { ing-1000 ppm }<\text { PTFE coating-2000 ppm }< \\
\text { Without coating-2000 ppm }\end{array}$ \\
\hline Kinetics models & $\begin{array}{l}\text { Ambient pressure and temperature, Electric } \\
\text { field strength } 2 \mathrm{kV} / \mathrm{cm}\end{array}$ & \multicolumn{2}{|c|}{$\begin{array}{l}\text { Calculated } \mathrm{Q}_{\mathrm{e}} \approx \text { experimental } \mathrm{Q}_{\mathrm{e}} \\
\text { Maximum amount of deposition: During the first } 2 \mathrm{~min} \\
\text { Deposition reduction } \approx 56 \% \text { (static state, } 2000 \mathrm{ppm}) \\
\text { Deposition reduction } \approx 70 \% \text { (dynamic state, } 2000 \mathrm{ppm} \text { ) } \\
\text { Best agreement with the experimental data: nth-order kinetics model in static state, } \\
\text { double exponential model in dynamic state }\end{array}$} \\
\hline
\end{tabular}

Table 1. Summary of the most important results.

\begin{tabular}{|l|l|l|l|}
\hline & & Test number & Type of working electrode \\
\hline \multirow{4}{*}{ Parameter } & \multirow{3}{*}{ Parameter } & 1 & Without coating \\
\cline { 3 - 5 } & & 3 & PTFE coating \\
\cline { 2 - 4 } & \multirow{2}{*}{ Constant } & $\begin{array}{l}\text { Electric field application time }(5,10,20,40,60,80,120,180,300 \mathrm{~s}) \\
\text { Electric field strength } 2 \mathrm{kV} / \mathrm{cm}, 4 \% \text { toluene concentration, } 2000 \mathrm{ppm} \text { asphaltene concentration, static state }\end{array}$ \\
\hline
\end{tabular}

Table 2. The design of experiments to investigate the effect of coating type on asphaltene deposition in static sate.

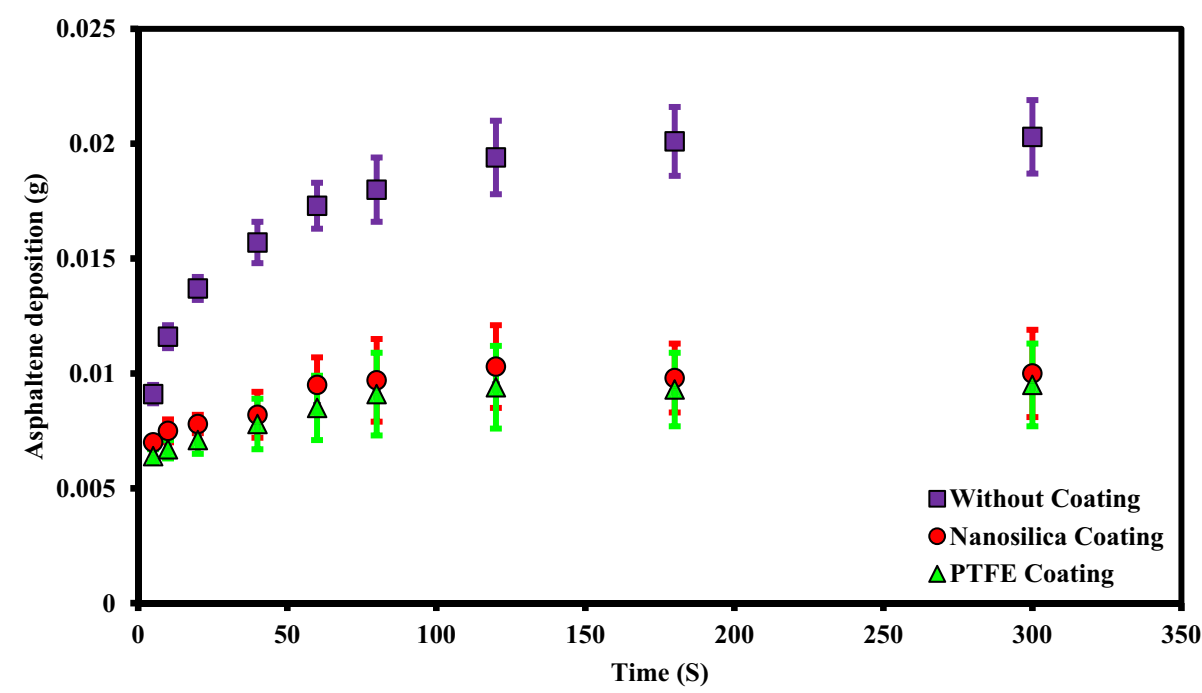

Figure 4. Asphaltene deposition rate on uncoated and coated electrodes for different exposure times to electric field at ambient pressure and temperature (Asphaltene concentration $2000 \mathrm{ppm}$, Electric field strength $2 \mathrm{kV} /$ $\mathrm{cm})$.

asphaltene deposits must have the required surface characteristics for this purpose. The creation of superhydrophobic coatings with low surface energy could change the solid surface sites to non-polar ${ }^{56,57}$ and ultimately reduces the tendency of asphaltene deposition on the coated surfaces ${ }^{58-64}$. Therefore, such a surface can not only prevent the deposition of minerals in formation water, but also can significantly reduce the deposition of asphaltene. Superhydrophilic surfaces could also effectively block the access of asphaltene to the surface by creating a 


\begin{tabular}{|l|l|l|l|l|l|l|l|}
\hline & & \multicolumn{2}{l}{ Without coating } & \multicolumn{2}{l|}{ PTFE coating } & \multicolumn{2}{l|}{ Nanosilica coating } \\
\cline { 3 - 8 } Test number & Test duration $(\mathbf{s})$ & Weight $(\mathbf{g})$ & Percent & Weight $(\mathbf{g})$ & Percent & Weight $(\mathbf{g})$ & Percent \\
\hline 1 & 5 & 0.0091 & 11.3 & 0.0064 & 8.0 & 0.0070 & 8.7 \\
\hline 2 & 10 & 0.0116 & 14.5 & 0.0067 & 8.3 & 0.0075 & 9.3 \\
\hline 3 & 20 & 0.0137 & 17.1 & 0.0071 & 8.8 & 0.0078 & 9.7 \\
\hline 4 & 40 & 0.0157 & 19.6 & 0.0078 & 9.7 & 0.0082 & 10.2 \\
\hline 5 & 60 & 0.0173 & 21.6 & 0.0085 & 10.6 & 0.0095 & 11.8 \\
\hline 6 & 80 & 0.0180 & 22.5 & 0.0091 & 11.3 & 0.0097 & 12.1 \\
\hline 7 & 120 & 0.0194 & 24.2 & 0.0094 & 11.7 & 0.0103 & 12.8 \\
\hline 8 & 180 & 0.0201 & 25.1 & 0.0093 & 11.6 & 0.0098 & 12.2 \\
\hline 9 & 300 & 0.0203 & 25.3 & 0.0095 & 11.8 & 0.0100 & 12.5 \\
\hline
\end{tabular}

Table 3. Asphaltene deposition on uncoated, PTFE-coated and nanosilica coated electrodes for different exposure times to electric field. Deposition value (electric field strength $2 \mathrm{kV} / \mathrm{cm}, 4 \%$ toluene concentration, $2000 \mathrm{ppm}$ asphaltene concentration, static state).

\begin{tabular}{|c|c|c|c|c|}
\hline & & Test number & Flow state & Type of working electrode \\
\hline \multirow{5}{*}{ Parameter } & \multirow{4}{*}{ Variable } & \multirow{2}{*}{1} & \multirow{2}{*}{ Static } & Without coating \\
\hline & & & & PTFE coating \\
\hline & & \multirow{2}{*}{2} & \multirow{2}{*}{ Dynamic } & Without coating \\
\hline & & & & PTFE coating \\
\hline & Constant & $\begin{array}{l}\text { Electric field a } \\
\text { Electric field s }\end{array}$ & asphaltene & centration \\
\hline
\end{tabular}

Table 4. The design of experiments to investigate the effect of flow type on the amount of asphaltene deposition.

water film, and therefore reduce the asphaltene deposition ${ }^{65}$, however, having a water film on the surface could initiate the deposition of inorganic scales and creation of suitable sites for organic deposits and also corrosion.

The effect of flow type on the amount of asphaltene deposition. An experiment was designed to investigate the effect of shear rate on the amount of asphaltene deposition on electrode surfaces with and without superhydrophobic coating. In this regard, two parameters (flow state and type of working electrode) were considered as variables. Experiments were performed for two types of flow and working electrodes (without coating electrode and PTFE superhydrophobic coating electrode). In a dynamic state, the oil sample solution was agitated using a magnetic stirrer at $400 \mathrm{rpm}$ and the amount of deposition on the surfaces with and without coating was measured. During these experiments, other influential parameters such as voltage, toluene concentration, asphaltene concentration, and time were kept constant. The parameters adjusted in the design of the experiment are shown in Table 4. The amount of asphaltene deposition on uncoated and superhydrophobic PTFE coated electrodes under static and dynamic conditions after $300 \mathrm{~s}$ of electrodeposition is shown in Fig. 5. The detailed test results are reported in Table 5. It should be noted that measurements were made at ambient pressure and temperature. According to the results, hydrophobic properties decrease the adhesion force between the surface and the deposition. The amount of asphaltene deposition in the dynamic state for the uncoated and the superhydrophobic PTFE-coated electrodes is far less than in other cases. Dynamic deposition for PTFE superhydrophobic coating is far less than the other cases.

The effect of asphaltene concentration on the amount of asphaltene deposition. An experiment was designed to investigate the kinetics of asphaltene deposition on superhydrophobic PTFE-coated electrodes for three different asphaltene concentrations. During these experiments, other influential parameters such as voltage, toluene concentration and coating type were kept constant. The parameters used in the design of the experiment are listed in Table 6. Experiments were performed for asphaltene concentrations of 2000, 1000 and $250 \mathrm{ppm}$ and different exposure times up to $5 \mathrm{~min}$. The amount of asphaltene deposition as a function of asphaltene concentration in the static and dynamic states for the PTFE superhydrophobic coated electrodes is shown in Fig. 6. The detailed information for this experiment can be found in Tables 7 and 8 . Figures 7 and 8 also compare the amount of deposition at different asphaltene concentrations in static and dynamic states. It is observed that decreasing the asphaltene concentration and the duration of the electrodeposition process decrease the amount of asphaltene deposition in the static and dynamic states for PTFE superhydrophobic coatings. The amount of asphaltene deposition at all three concentrations and dynamic state is lower than that in the static state. As shown in Fig. 7, the amount of asphaltene deposition after $300 \mathrm{~s}$ at a concentration of $2000 \mathrm{ppm}$ for PTFE superhydrophobic coating is lower than that for nanosilica coating. The reason for this result can be related to the functional groups on the surface of nanosilica coatings and asphaltene. H-bonding sites of surface 


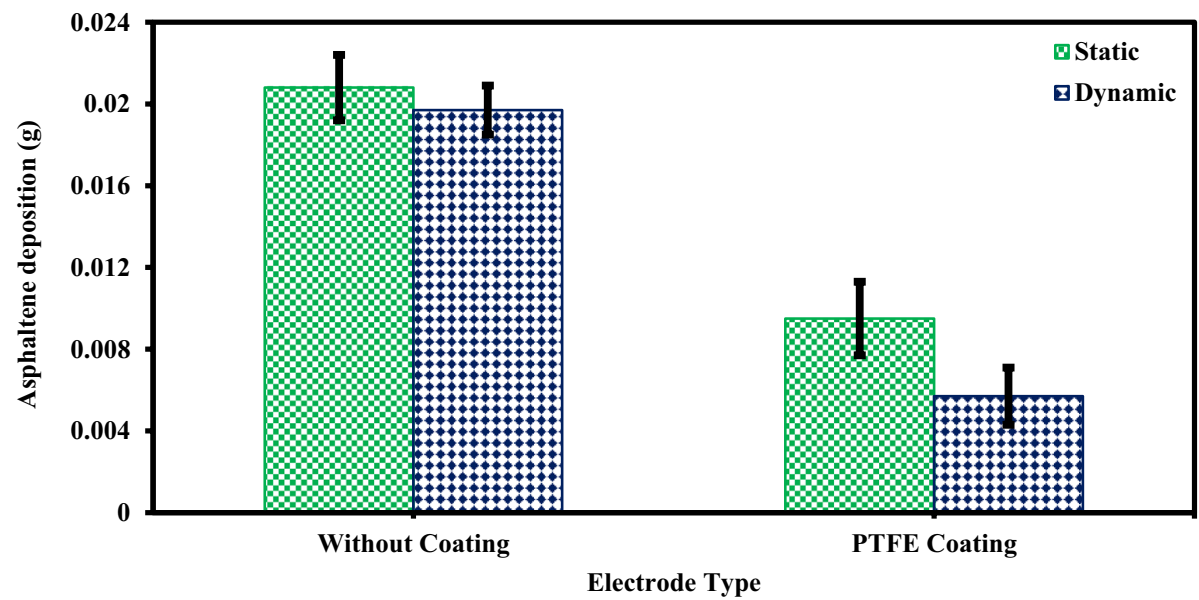

Figure 5. Comparison of asphaltene deposition on uncoated and PTFE coated electrodes after $300 \mathrm{~s}$ of exposure to electric filed and for asphaltene concentration of $2000 \mathrm{ppm}$ at ambient pressure and temperature.

\begin{tabular}{|c|c|c|c|c|c|c|c|c|c|}
\hline \multirow[b]{3}{*}{ Test number } & \multirow[b]{3}{*}{ Test duration (s) } & \multicolumn{4}{|c|}{ Without coating } & \multicolumn{4}{|c|}{ PTFE coating } \\
\hline & & \multicolumn{2}{|l|}{ Static } & \multicolumn{2}{|l|}{ Dynamic } & \multicolumn{2}{|l|}{ Static } & \multicolumn{2}{|l|}{ Dynamic } \\
\hline & & Weight (g) & Percent & Weight (g) & Percent & Weight (g) & Percent & Weight (g) & Percent \\
\hline 1 & 5 & 0.0091 & 11.3 & 0.0078 & 9.7 & 0.0064 & 8.0 & 0.0051 & 6.3 \\
\hline 2 & 10 & 0.0116 & 14.5 & 0.0096 & 12.0 & 0.0067 & 8.3 & 0.0058 & 7.2 \\
\hline 3 & 20 & 0.0137 & 17.1 & 0.0102 & 12.7 & 0.0071 & 8.8 & 0.0063 & 8.8 \\
\hline 4 & 40 & 0.0157 & 19.6 & 0.0142 & 17.7 & 0.0078 & 9.7 & 0.0069 & 8.6 \\
\hline 5 & 60 & 0.0173 & 21.6 & 0.0151 & 18.8 & 0.0085 & 10.6 & 0.0077 & 9.6 \\
\hline 6 & 80 & 0.0180 & 22.5 & 0.0169 & 21.1 & 0.0091 & 11.3 & 0.0084 & 10.5 \\
\hline 7 & 120 & 0.0194 & 24.2 & 0.0183 & 22.8 & 0.0094 & 11.7 & 0.0086 & \begin{tabular}{|l|}
10.7 \\
\end{tabular} \\
\hline 8 & 180 & 0.0201 & 25.1 & 0.0191 & 23.8 & 0.0093 & 11.6 & 0.0088 & 11.0 \\
\hline 9 & 300 & 0.0203 & 25.3 & 0.0190 & 23.7 & 0.0095 & 11.8 & \begin{tabular}{|l|}
0.0087 \\
\end{tabular} & \begin{tabular}{|l|}
10.8 \\
\end{tabular} \\
\hline
\end{tabular}

Table 5. Asphaltene deposition rate for uncoated and PTFE coated electrodes in static and dynamic states. Deposition value (electric field strength $2 \mathrm{kV} / \mathrm{cm}, 4 \%$ toluene concentration, $2000 \mathrm{ppm}$ asphaltene concentration).

\begin{tabular}{|c|c|c|c|c|c|}
\hline & & Test number & Asphaltene concentration (ppm) & Asphaltene content (g) & Flow state \\
\hline \multirow{7}{*}{ Parameter } & \multirow{6}{*}{ Variable } & \multirow{2}{*}{1} & \multirow{2}{*}{2000} & \multirow{2}{*}{0.08} & Static \\
\hline & & & & & Dynamic \\
\hline & & \multirow{2}{*}{2} & \multirow{2}{*}{1000} & \multirow{2}{*}{0.04} & Static \\
\hline & & & & & Dynamic \\
\hline & & \multirow{2}{*}{3} & \multirow{2}{*}{250} & \multirow{2}{*}{0.01} & Static \\
\hline & & & & & Dynamic \\
\hline & Constant & \multicolumn{4}{|c|}{$\begin{array}{l}\text { Electric field application time }(5,10,20,40,60,80,120,180,300 \mathrm{~s}) \\
\text { Electric field strength } 2 \mathrm{kV} / \mathrm{cm}, 4 \% \text { toluene concentration, PTFE coating }\end{array}$} \\
\hline
\end{tabular}

Table 6. The design of experiments to investigate the effect of concentration on the amount of asphaltene deposition.

hydroxyls, in the nanosilica superhydrophobic coating, formed by modification with silane material (DTMS), can be effective in adsorbing active groups in the asphaltene surface such as carboxylic. Some studies have also confirmed the effect of interaction between surface active sites of asphaltenes and sorbent surface active sites $^{61}$. In PTFE coating, there is no interaction between fluorine in PTFE coating and asphaltene particles, and therefore the amount of asphaltene deposition in PTFE superhydrophobic coating will be less than nanosilica superhydrophobic coating. In this experiment, due to high the concentration and opacity of the solution, the movement of asphaltene particles at a concentration of $2000 \mathrm{ppm}$ at the beginning and end of the experiment was not observed. As the concentration of asphaltene decreased, the movement of the particles in the form of 


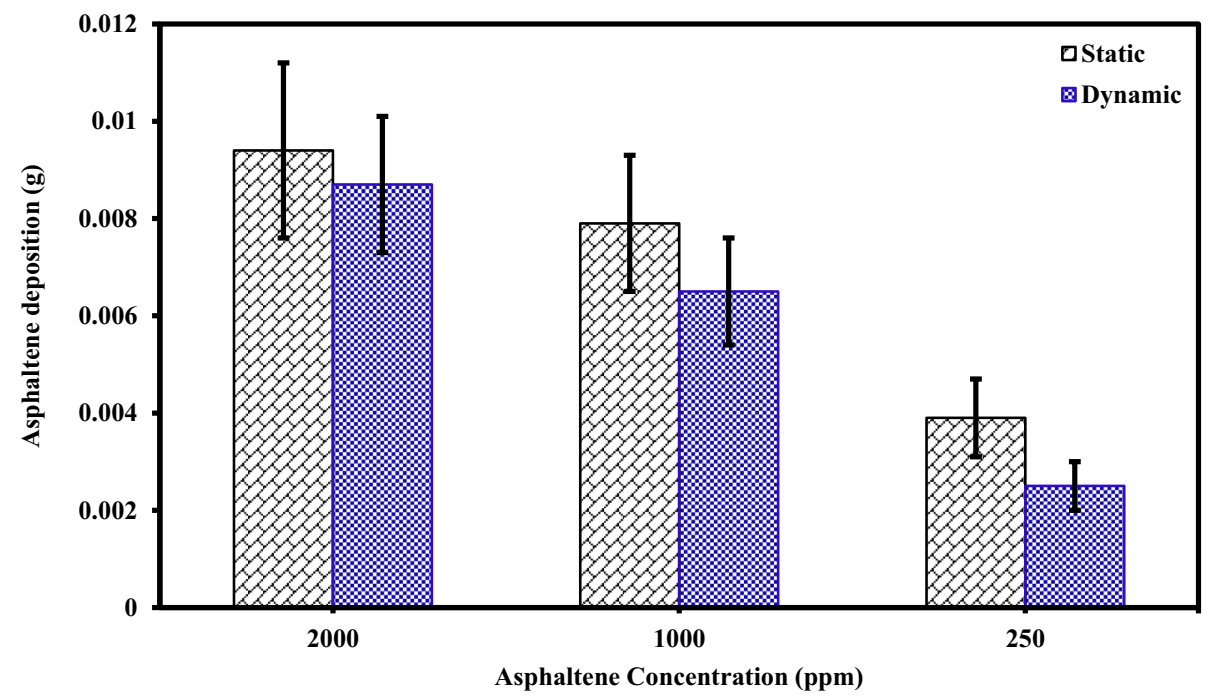

Figure 6. The effect of asphaltene concentration on asphaltene deposition for PTFE coating in static and dynamic states at ambient pressure and temperature.

\begin{tabular}{|c|c|c|c|c|c|c|c|}
\hline \multirow[b]{2}{*}{ Test numbe } & \multirow[b]{2}{*}{ Test duration (s) } & \multicolumn{2}{|c|}{\begin{tabular}{|l|} 
Concentration \\
$(2000$ ppm)
\end{tabular}} & \multicolumn{2}{|c|}{\begin{tabular}{|l|} 
Concentration \\
$(1000$ ppm $)$
\end{tabular}} & \multicolumn{2}{|c|}{$\begin{array}{l}\text { Concentration } \\
(250 \mathrm{ppm})\end{array}$} \\
\hline & & Weight (g) & Percent & Weight (g) & Percent & Weight (g) & Percent \\
\hline 1 & 5 & 0.0064 & 8.0 & 0.0042 & 10.5 & 0.0014 & 14.0 \\
\hline 2 & 10 & 0.0067 & 8.3 & 0.0044 & 11.0 & 0.0018 & 18.0 \\
\hline 3 & 20 & 0.0071 & 8.8 & 0.0047 & 11.7 & 0.0022 & 22.0 \\
\hline 4 & 40 & 0.0078 & 9.7 & 0.0052 & 13.0 & 0.0026 & 26.0 \\
\hline 5 & 60 & 0.0085 & 10.6 & 0.0061 & 15.2 & 0.0031 & 31.0 \\
\hline 6 & 80 & 0.0091 & 11.3 & 0.0062 & 15.5 & 0.0035 & 35.0 \\
\hline 7 & 120 & 0.0094 & 11.7 & 0.0078 & 19.5 & 0.0039 & 39.0 \\
\hline 8 & 180 & 0.0093 & 11.6 & 0.0080 & 20.0 & 0.0041 & 41.0 \\
\hline 9 & 300 & 0.0095 & 11.8 & 0.0079 & 19.7 & 0.0038 & 38.0 \\
\hline
\end{tabular}

Table 7. Asphaltene deposition rate on PTFE coated electrode in static state for different asphaltene concentrations and exposure time to electric filed. Deposition value (electric field strength $2 \mathrm{kV} / \mathrm{cm}, 4 \%$ toluene concentration, PTFE coating, static state).

\begin{tabular}{|c|c|c|c|c|c|c|c|}
\hline \multirow[b]{2}{*}{ Test number } & \multirow[b]{2}{*}{ Test duration (s) } & \multicolumn{2}{|c|}{\begin{tabular}{|l} 
Concentration \\
(2000 ppm)
\end{tabular}} & \multicolumn{2}{|c|}{$\begin{array}{l}\text { Concentration } \\
\text { (1000 ppm) }\end{array}$} & \multicolumn{2}{|c|}{$\begin{array}{l}\text { Concentration } \\
(250 \mathrm{ppm})\end{array}$} \\
\hline & & Weight (g) & Percent & Weight (g) & Percent & Weight (g) & Percent \\
\hline 1 & 5 & 0.0051 & 6.3 & 0.0033 & 8.2 & 0.0006 & 6.0 \\
\hline 2 & 10 & 0.0058 & 7.2 & 0.0036 & 9.0 & 0.0007 & 7.0 \\
\hline 3 & 20 & 0.0063 & 7.8 & 0.0039 & 9.7 & 0.0013 & 13.0 \\
\hline 4 & 40 & 0.0069 & 8.6 & 0.0044 & 11.0 & 0.0016 & 16.0 \\
\hline 5 & 60 & 0.0077 & 9.6 & 0.0053 & 13.2 & 0.0018 & 18.0 \\
\hline 6 & 80 & 0.0084 & 10.5 & 0.0057 & 14.2 & 0.0023 & 23.0 \\
\hline 7 & 120 & 0.0086 & 10.7 & 0.0062 & 15.5 & 0.0025 & 25.0 \\
\hline 8 & 180 & 0.0088 & 11.0 & 0.0072 & 18.0 & 0.0028 & 28.0 \\
\hline 9 & 300 & 0.0087 & 10.8 & 0.0065 & 16.2 & 0.0024 & 24.0 \\
\hline
\end{tabular}

Table 8. Asphaltene deposition rate for PTFE coated electrode in dynamic state for different asphaltene concentrations and exposure time to electric field. Deposition value (electric field strength $2 \mathrm{kV} / \mathrm{cm}, 4 \%$ toluene concentration, PTFE coating, dynamic state). 


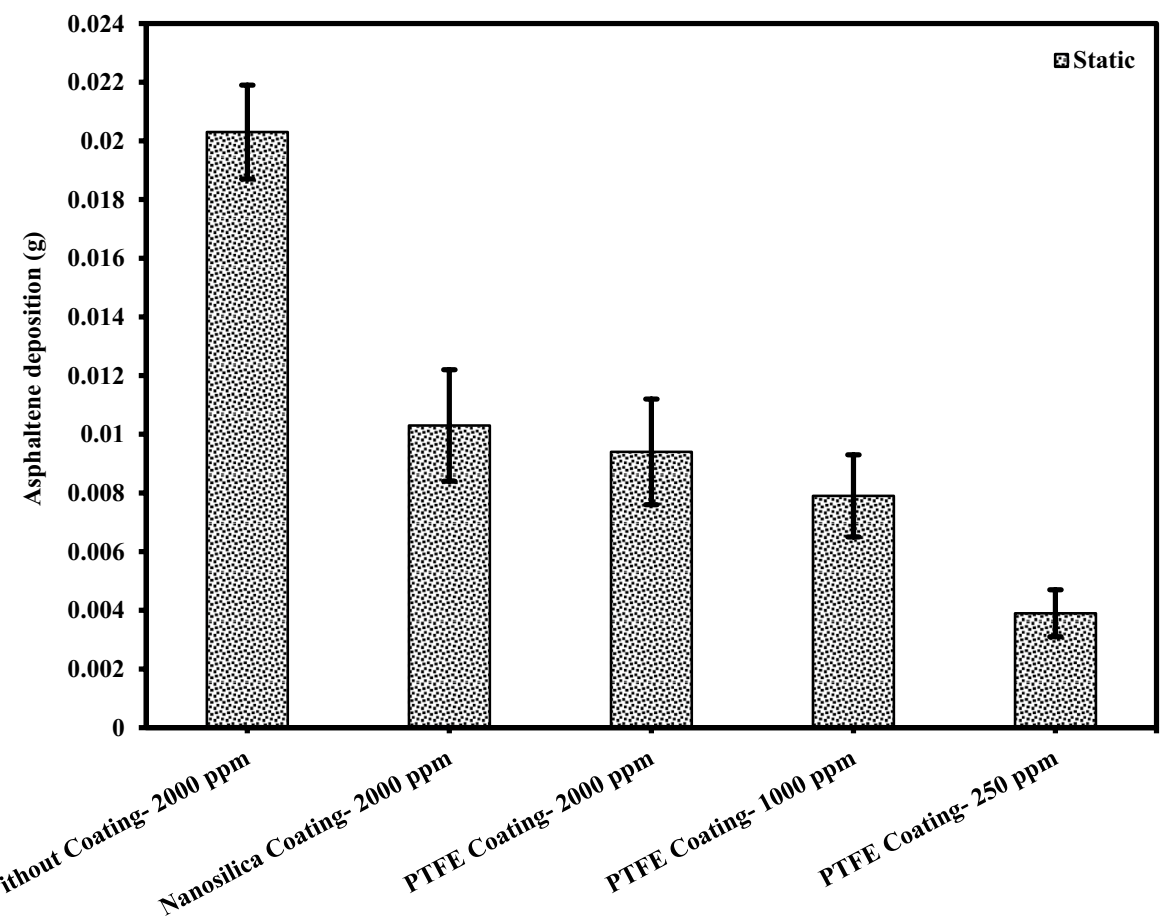

Figure 7. Comparison of coated and uncoated electrodes based on the amount of deposition at different asphaltene concentrations in static state at ambient pressure and temperature (The amount of asphaltene deposition were reported at the end of 300 s period).

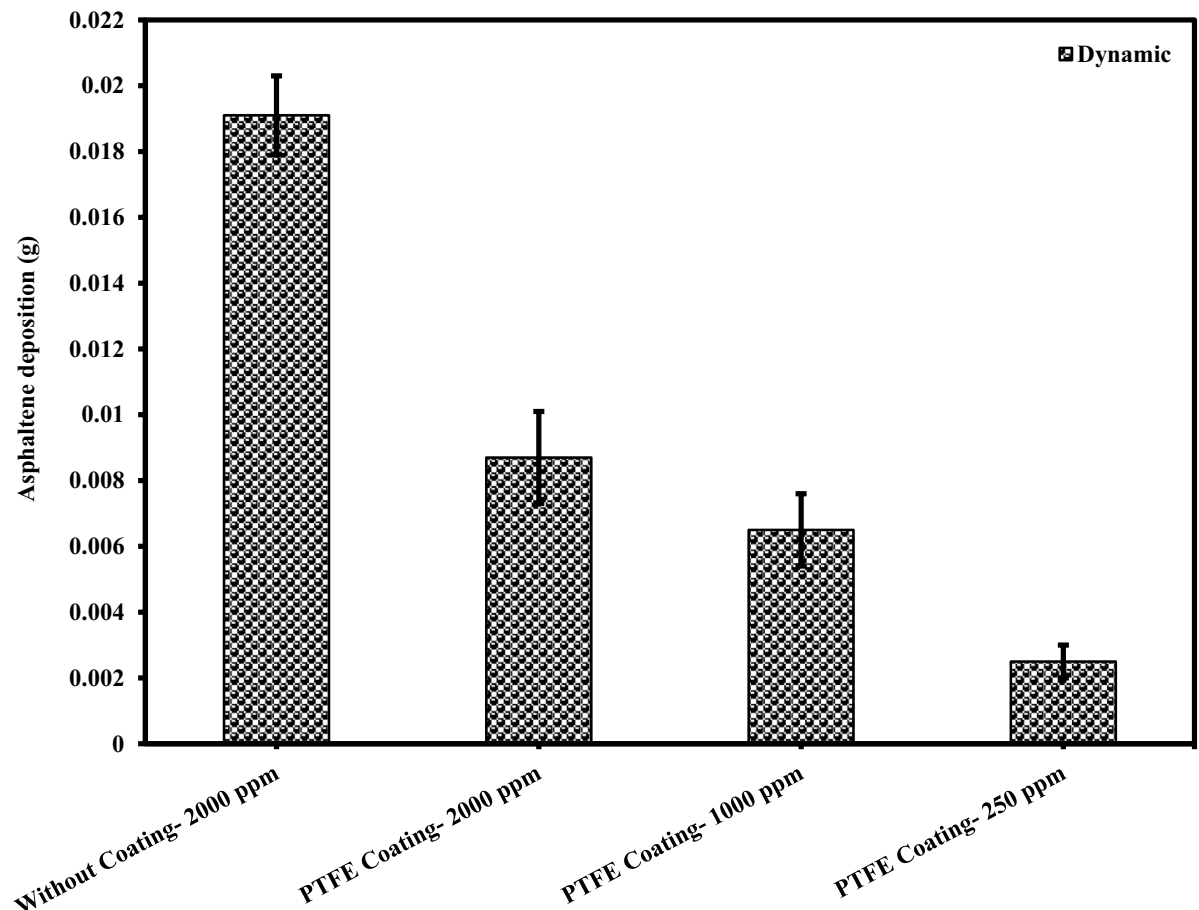

Figure 8. Comparison of coated and uncoated electrodes based on the amount of deposition at different asphaltene concentrations in dynamic state at ambient pressure and temperature (The amount of asphaltene deposition were reported at the end of $300 \mathrm{~s}$ period). 
dark masses toward the electrodes became evident. In this experiment, the amount of asphaltene deposition in a short time on the superhydrophobic coated electrodes, especially PTFE superhydrophobic coated electrode, at the static state and $250 \mathrm{ppm}$, was very low and close to zero, and no traces of deposition were observed in a short time (Table 7). In contrast, the deposition rate at $250 \mathrm{ppm}$, in the static state on the uncoated electrode, was significantly high (Supplementary Fig. S.1). Experiments with dynamic states showed very small deposition rates at longer times for superhydrophobic PTFE coating (Table 8 and Fig. 8). It can be inferred that the hydrophobic property of the coating reduces the crude oil affinity for sticking to the surface ${ }^{26}$ and therefore, at lower concentrations the amount of asphaltene deposition is very low. It should be noted that the reason for a high CA and low SA in superhydrophobic surfaces is the low surface energy along with the hierarchical structure of the surface. As these two properties are enhanced at the surface, the existing surface becomes more hydrophobic until it reaches the superhydrophobicity ${ }^{66}$. The superhydrophobic and low sliding angle characteristic of the produced PTFE superhydrophobic coating could be considered as the main reason for reducing asphaltene deposition. The surface roughness of the coatings was measured using the AFM method, and some roughness characteristics including average surface roughness (Ave Rough), root mean square roughness (RMS Rough) and mean height roughness (Mean Ht) of the samples were calculated. Figure 1b,e show 3D roughness images of PTFE and nanosilica superhydrophobic coatings measured by AFM. The roughness characteristics of the coatings are listed in Supplementary Table S.1. As can be seen in this table, the average surface roughness of PTFE and nanosilica superhydrophobic coatings is $1.255 \mu \mathrm{m}$ and $611.2 \mathrm{~nm}$, respectively. The roughness plays a major role in surface wettability and consequently in asphaltene deposition. Our objective in synthesizing the coatings was to obtain superhydrophobic surfaces with very low sliding angles. It was achieved by combining low surface energy and desired roughness in PTFE superhydrophobic coatings and generating a rough surface and later modifying the surface energy in nanosilica coating. Creating roughness on the surface increases the surface area and then reduces its energy. Therefore, low surface energy is considered as the main factor in superhydrophobic properties of the surface and roughness is the aggravating factor ${ }^{67}$.

Modeling of asphaltene deposition kinetics on coated and uncoated electrodes. The kinetic behavior of asphaltene deposition was modeled based on the results obtained in the previous sections. These models are appropriate for adsorption processes, however, their usage for deposition/adsorption processes (this study), provides a suitable insight into the kinetics of the deposition/adsorption process. Table 9 shows the parameters of the kinetic models for the coated and uncoated electrodes at different concentrations. The results of the deposition model are as follows.

Modified second-order model. In this model, $K_{2}$ values for the static state were found to be $0.0153-0.0633 \mathrm{~cm}^{2} /$ $\mathrm{mg} \times \min$ and $0.0205-0.0502 \mathrm{~cm}^{2} / \mathrm{mg} \times \min$ for the dynamic state. The values of $\beta_{2}$ for the static state are in the range of 1.2896-2.6511 and for the dynamic state are in the range of 1.0834-1.8605.

Double exponential model. There are usually two steps in the asphaltene deposition process. The first involves the rapid deposition rate and the second step is related to the slow adsorption until equilibrium is reached. As the initial concentration of asphaltenes increases, this period will be longer. The initial rate of asphaltene buildup on a surface could be different from that at the later stages and this makes the two-step models a suitable choice for adsorption modeling. This behavior was also modeled in a study by Refs. ${ }^{12,68}$ who used quartz crystal microbalance with dissipation (QCM-D) measurements and examined the process of asphaltene adsorption for short and long times. Our results show that the $R F$ value in static and dynamic states for the uncoated electrode is higher than that of the $S F$, indicating that this process is faster for the uncoated electrode. For the PTFE coating, the $R F$ and $S F$ values in static and dynamic states do not show any particular trend. In the dynamic state for the uncoated electrode at a concentration of $2000 \mathrm{ppm}$, the $R F$ value is almost 100.0000 and the $S F$ value is 0.0000 and in this state, the $R F$ value for the PTFE coated electrode in $2000 \mathrm{ppm}$, is 100.0000 and the value of $S F$ is 0.0000 . This indicates that, under these conditions, the asphaltene deposition process happens only in the first step, i.e., during the rapid step and there is no slow deposition step under these conditions. The $R F$ value for nanosilica coating and the concentration of $2000 \mathrm{ppm}$ in a static state is lower than the $S F$ value. This indicates that the slow deposition process is faster for this coating. The $R F$ value for the dynamic state and the PTFE coating increases with increasing initial concentration $(250,1000$, and 2000), and no specific trend is observed for the static state. The range of $K_{D 1}$ values for the static state and dynamic state is $0.0103-0.0391$ and $0.0170-$ 0.0261 , respectively. Also, the range of $K_{D 2}$ values for the static state is $0.0032-0.0039$ and for the dynamic state is $0.0036-0.0083$.

nth-Order kinetics model. The order of the deposition reaction, $n$, for the coatings in static and dynamic states decreases with the increasing initial concentration of asphaltene. Its value was calculated for the static state between 1.0153 and 1.2680 and for the dynamic state between 1.1091 and $1.5429 . K_{n}$ values were calculated for static state in the range of $0.0114-0.0794(1 / \mathrm{min}) \times\left(\mathrm{mg} / \mathrm{cm}^{2}\right)^{1-\mathrm{n}}$ and $0.0166-0.0467(1 / \mathrm{min}) \times\left(\mathrm{mg} / \mathrm{cm}^{2}\right)^{1-\mathrm{n}}$ for the dynamic state. The $\beta_{n}$ values for static and dynamic states were approximately 1 . This means that initially there were no impurities or pre-adsorbed asphaltenes.

Elovich's equation model. The deposition constant, $a$, for the static state and PTFE coatings is in the range 2291.0842-93,806.7807 and for the dynamic state and the PTFE coatings are in the range 407.6974-32,803.008 and increase with increasing concentration. Its value for nanosilica coating at static state and concentration of $2000 \mathrm{ppm}$ is $873,019.4700$ which is higher than 93,806.7807 for PTFE coating under these conditions. The value of this constant for the uncoated electrode at the static state and concentration of $2000 \mathrm{ppm}$ is 1580.9478 


\begin{tabular}{|c|c|c|c|c|c|c|c|c|c|}
\hline \multirow{3}{*}{$\begin{array}{l}\text { Flow type } \\
\mathrm{C}_{\mathrm{i}} \text { (initial conc.), } \\
\text { ppm } \\
\text { Type of coating }\end{array}$} & \multicolumn{5}{|l|}{ Static } & \multicolumn{4}{|l|}{ Dynamic } \\
\hline & \multicolumn{3}{|l|}{$2000 \mathrm{ppm}$} & \multirow{2}{*}{\begin{tabular}{|l|}
$1000 \mathrm{ppm}$ \\
PTFE coating \\
\end{tabular}} & \multirow{2}{*}{$\begin{array}{l}250 \mathrm{ppm} \\
\text { PTFE coating }\end{array}$} & \multicolumn{2}{|l|}{$2000 \mathrm{ppm}$} & \multirow{2}{*}{\begin{tabular}{|l|}
$1000 \mathrm{ppm}$ \\
PTFE coating \\
\end{tabular}} & \multirow{2}{*}{\begin{tabular}{|l|}
$250 \mathrm{ppm}$ \\
PTFE coating
\end{tabular}} \\
\hline & Without coating & Nano silica & PTFE coating & & & Without coating & PTFE coating & & \\
\hline $\mathrm{Q}_{\mathrm{e}}, \exp .(\mathrm{mg} / \mathrm{g})$ & 0.0203 & 0.0100 & 0.0095 & 0.0079 & 0.0038 & 0.0190 & 0.0087 & 0.0065 & 0.0024 \\
\hline \multicolumn{10}{|c|}{ Modified second-order model } \\
\hline $\mathrm{Q}_{\mathrm{e}},(\mathrm{mg} / \mathrm{g})$ & 0.0223 & 0.0103 & 0.0106 & 0.0098 & 0.0045 & 0.0209 & 0.0092 & 0.0084 & 0.0023 \\
\hline $\mathrm{k}_{2}\left(\mathrm{~min}^{-1}\right)$ & 0.0633 & 0.0616 & 0.0572 & 0.0153 & 0.0450 & 0.0376 & 0.0502 & 0.0205 & 0.0438 \\
\hline$\beta$ & 1.4346 & 2.6511 & 2.4077 & 1.7292 & 1.2896 & 1.3210 & 1.8605 & 1.5646 & 1.0834 \\
\hline RMSE & 0.0022 & 0.0020 & 0.0020 & 0.0013 & 0.0004 & 0.0017 & 0.0014 & 0.0010 & 0.0003 \\
\hline AAPRE & 3.7993 & 4.0539 & 5.1657 & 5.6452 & 8.1876 & 5.0662 & 4.2933 & 5.3239 & 13.3185 \\
\hline \multicolumn{10}{|c|}{ Double exponential model } \\
\hline $\mathrm{Q}_{\mathrm{e}},(\mathrm{mg} / \mathrm{g})$ & 0.0219 & 0.0118 & 0.0093 & 0.0105 & 0.0052 & 0.0194 & 0.0087 & 0.0070 & 0.0038 \\
\hline $\mathrm{D}_{1}$ & 0.0101 & 0.0014 & 0.0030 & 0.0014 & 0.0019 & 0.0128 & 0.0041 & 0.0025 & 0.0015 \\
\hline $\mathrm{D}_{2}$ & 0.0032 & 0.0027 & 0.0008 & 0.0047 & 0.0021 & 0.0000 & 0.0000 & 0.0014 & 0.0018 \\
\hline $\mathrm{K}_{\mathrm{D} 1}$ & 0.0334 & 0.0304 & 0.0269 & 0.0103 & 0.0391 & 0.0204 & 0.0261 & 0.0170 & 0.0247 \\
\hline $\mathrm{K}_{\mathrm{D} 2}$ & 0.0039 & 0.0039 & 0.0039 & 0.0043 & 0.0032 & 0.0043 & 0.0039 & 0.0083 & 0.0036 \\
\hline RF, \% & 76.0460 & 35.4133 & 78.8023 & 23.7974 & 46.9985 & 100.0000 & 100.0000 & 63.7058 & 44.4081 \\
\hline SF, \% & 23.9539 & 64.5866 & 21.1976 & 76.2025 & 53.0014 & 0.0000 & 0.0000 & 36.2941 & 55.5918 \\
\hline RMSE & 0.0028 & 0.0024 & 0.0017 & 0.0014 & 0.0004 & 0.0021 & 0.0014 & 0.0009 & 0.0002 \\
\hline AAPRE & 4.0802 & 6.6685 & 5.4571 & 5.3771 & 8.2962 & 2.4953 & 1.7973 & 3.0413 & 7.9853 \\
\hline $\mathrm{Q}_{\mathrm{e}}, \exp .(\mathrm{mg} / \mathrm{g})$ & 0.0203 & 0.0100 & 0.0095 & 0.0079 & 0.0038 & 0.0190 & 0.0087 & 0.0065 & 0.0024 \\
\hline \multicolumn{10}{|c|}{ nth-order kinetic model } \\
\hline $\mathrm{Q}_{\mathrm{e}}$, cal., (mg/g) & 0.0228 & 0.0100 & 0.0095 & 0.0084 & 0.0041 & 0.0239 & 0.0086 & 0.0072 & 0.0025 \\
\hline$\beta_{\mathrm{n}}$ & 1.5796 & 1.0163 & 1.0541 & 1.1881 & 1.0593 & 1.5306 & 1.0854 & 1.0993 & 1.0346 \\
\hline $\mathrm{k}_{\mathrm{n}}\left(\mathrm{min}^{-1}\right)$ & 0.0794 & 0.0295 & 0.0210 & 0.0114 & 0.0251 & 0.0422 & 0.0251 & 0.0166 & 0.0467 \\
\hline $\mathrm{n}$ & 2.5434 & 1.0153 & 1.0525 & 1.1920 & 1.2680 & 2.4707 & 1.1091 & 1.1693 & 1.5429 \\
\hline RMSE & 0.0018 & 0.0020 & 0.0019 & 0.0013 & 0.0003 & 0.0021 & 0.0014 & 0.0010 & 0.0002 \\
\hline AAPRE & 1.3565 & 2.3117 & 1.2594 & 3.3033 & 3.7448 & 5.4198 & 3.3659 & 5.0794 & 11.9815 \\
\hline \multicolumn{10}{|l|}{ Elovich's equation } \\
\hline $\mathrm{Q}_{\mathrm{e}},(\mathrm{mg} / \mathrm{g})$ & 0.0225 & 0.0107 & 0.0106 & 0.0080 & 0.0045 & 0.0197 & 0.0095 & 0.0062 & 0.0025 \\
\hline $\mathrm{a}$ & 1580.9478 & $873,019.4700$ & $93,806.7807$ & $16,475.2481$ & 2291.0482 & 537.1581 & $32,803.0080$ & 5943.5996 & \begin{tabular}{|l|l|}
407.6974 \\
\end{tabular} \\
\hline$\alpha$ & 323.0661 & 1147.4729 & 962.7946 & 1047.7282 & 1372.5937 & 316.1196 & 963.1319 & 1174.5895 & 1704.0341 \\
\hline RMSE & 0.0008 & 0.0004 & 0.0006 & 0.0005 & 0.0003 & 0.0009 & 0.0003 & 0.0005 & 0.0003 \\
\hline AAPRE & 4.7954 & 4.6750 & 6.7033 & 8.5840 & 11.0078 & 6.4137 & 4.7708 & 8.9519 & 15.5949 \\
\hline \multicolumn{10}{|l|}{ Diffusion } \\
\hline $\mathrm{Q}_{\mathrm{e}},(\mathrm{mg} / \mathrm{g})$ & 0.0240 & 0.0117 & 0.0125 & 0.0098 & 0.0059 & 0.0211 & 0.0112 & 0.0088 & 0.0044 \\
\hline $\mathrm{K}_{\mathrm{p}}$ & 0.0008 & 0.0002 & 0.0003 & 0.0003 & 0.0002 & 0.0008 & 0.0003 & 0.0003 & 0.0002 \\
\hline I & 0.0084 & \begin{tabular}{|l|}
0.0067 \\
\end{tabular} & 0.0056 & 0.0034 & 0.0009 & 0.0066 & 0.0048 & 0.0025 & 0.0001 \\
\hline RMSE & 0.0031 & 0.0022 & 0.0021 & 0.0012 & 0.0007 & 0.0027 & 0.0017 & 0.0011 & 0.0006 \\
\hline AAPRE & 9.0855 & 6.1164 & 8.3095 & 7.6125 & 12.7893 & 10.0604 & 7.4261 & 7.6431 & 20.4254 \\
\hline
\end{tabular}

Table 9. Parameters calculated for a variety of kinetic models.

and for this electrode at the dynamic state and concentration of $2000 \mathrm{ppm}$ is 537.1581. Comparison of these results shows that by changing the flow state from static to dynamic, the deposition constant for the coated and uncoated electrodes decreases. Also, the initial deposition rate, $\alpha$, for PTFE coatings at static and dynamic states increases with decreasing initial concentration. The value of this parameter for nanosilica coating in static state and concentration of $2000 \mathrm{ppm}$ is 1147.4729 ; therefore, its value in nanosilica coating at constant state and concentration is higher than PTFE coating.

Diffusion equation model. $K_{p}$ values for the uncoated electrode at $2000 \mathrm{ppm}$ for static and dynamic states is 0.0008 . The value of this parameter for PTFE coating in static and dynamic states at 1000 and $2000 \mathrm{ppm}$ is 0.0003 and for $250 \mathrm{ppm}$ is 0.0002 . For nanosilica coating in a static state and $2000 \mathrm{ppm}$, its value is 0.0002 , which is less than the corresponding value for PTFE coating. The values of $I$ also decrease with decreasing initial concentration of asphaltenes for static and dynamic states and their values for PTFE coating in the static state are between 0.0009 and 0.0056 and for the dynamic state are between 0.0001 and 0.0048 . The value for the nanosilica coating is 0.0067 and for the uncoated electrode at $2000 \mathrm{ppm}$, in a static state is 0.0084 and for the dynamic state is 0.0066. Comparison of the results for $K_{p}$ and $I$ show that their values in the dynamic state are always lower than those in the static state. 


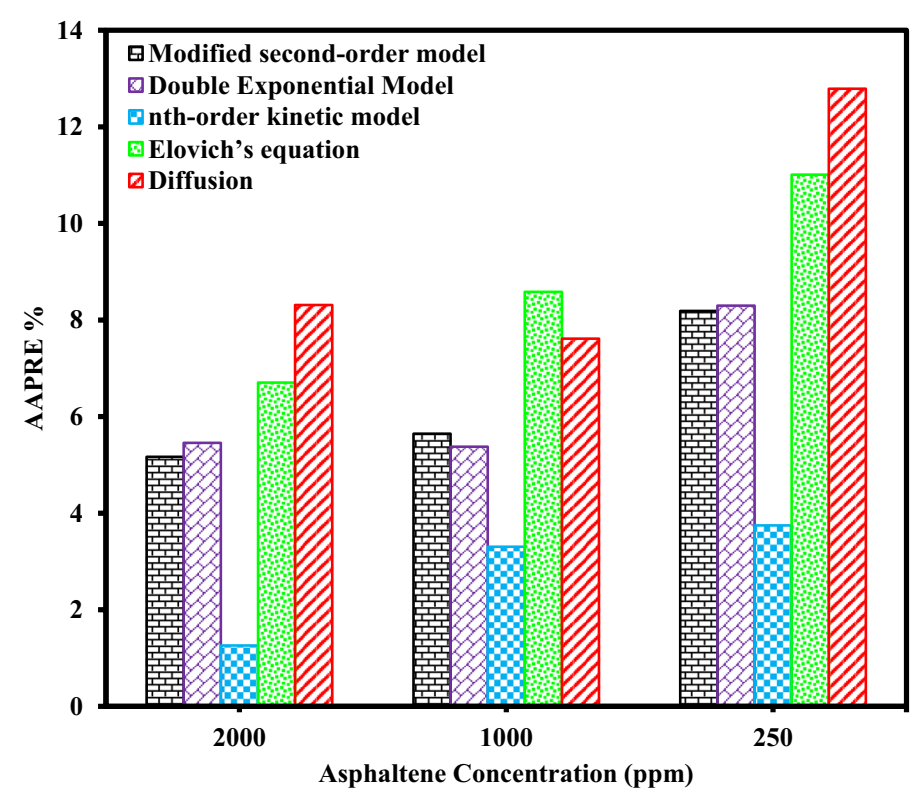

Figure 9. Comparison of deposition kinetics models at different asphaltene concentrations for PTFE coatings at static state based on AAPRE.

Evaluation of kinetic models. In this study, root mean square error (RMSE) and average absolute percent relative error $(A A P R E)$, as two statistical parameters, were used to evaluate and compare the accuracy of kinetic models. These parameters are calculated using Eqs. (10) and (11).

$$
\begin{gathered}
R M S E=\sqrt{\frac{1}{N} \sum_{i=1}^{N}\left(d_{\text {exp }, i}-d_{\text {pred }, i}\right)^{2}}, \\
A A P R E=\left(\frac{1}{N} \sum_{i=1}^{N} \frac{\left|d_{\text {exp }, i}-d_{\text {pred }, i}\right|}{d_{\text {exp }, i}}\right) \times 100 .
\end{gathered}
$$

Here, $d_{\text {exp,i }}$ and $d_{\text {pred,i }}$ represent experimental and calculated deposition values, respectively.

The results of calculated AAPRE and RMSE parameters for all kinetic models evaluated in this study are listed in Table 9. Figures 9, 10, Supplementary Figs. S.2, and S.3 show the comparison of AAPRE and RMSE for deposition kinetics models at different concentrations of asphaltenes for PTFE coatings, in static and dynamic states. Also in Figs. 11, 12, Supplementary Figs. S.4, and S.5 the deposition kinetics models for different coatings at concentrations of $2000 \mathrm{ppm}$ in static and dynamic states based on AAPRE and RMSE parameters are illustrated. Figures 13, 14, Supplementary Figs. S.6, and S.7 show the kinetic models that fit the experimental data for the uncoated electrode and the PTFE coated electrode at a concentration of $2000 \mathrm{ppm}$, in static and dynamic states. Figures 15 and 16 illustrate the agreement of the nth-order kinetics model to the experimental data in a static state for different concentrations and electrodes. Also, Supplementary Figs. S.8 and S.9 illustrate the agreement of the double exponential model to the experimental data in the dynamic state for different concentrations and electrodes. In all kinetic models, the calculated $Q_{e}$ values are approximately equal to the experimental $Q_{e}$ values.

As can be seen in these figures, the diffusion model and Elovich's equation do not fit well with the experimental data and have more errors than the other ones. The selection of suitable deposition kinetics models is based on the deposition process mechanism and application of different models. Based on the deposition kinetics data, it can be concluded that at the beginning of the asphaltene deposition process, the maximum amount of deposition occurs on the electrode surface (during the first $2 \mathrm{~min}$ ), and then the amount of deposition decreases. Also, based on these figures, it can be seen that the presence of a coating on the electrode surface caused a reduction of about $56 \%$ of the deposition in the static state at the concentration of $2000 \mathrm{ppm}$. Comparison of the amount of asphaltene deposition in the dynamic state for the coated electrodes shows more than $70 \%$ reduction in the amount of deposition at the same concentration, compared to the uncoated electrode. Regarding the RMSE values, in the static state, Elovich's equation and based on AAPRE values, the nth-order kinetics model showed the best fit to the experimental data. For the dynamic state and based on the RMSE parameter, Elovich's equation, has the best fit to the experimental data, and from AAPRE comparison, the double exponential model shows better agreement with the experimental data. Comparison of both parameters at all concentrations shows that in the static state, the nth-order kinetics model and in the dynamic state, the double exponential model, have the best agreement with the experimental data. Figure 17 shows the agreement of the experimental data and the best deposition kinetic models in static and dynamic states for PTFE coating electrodes at different concentrations. 


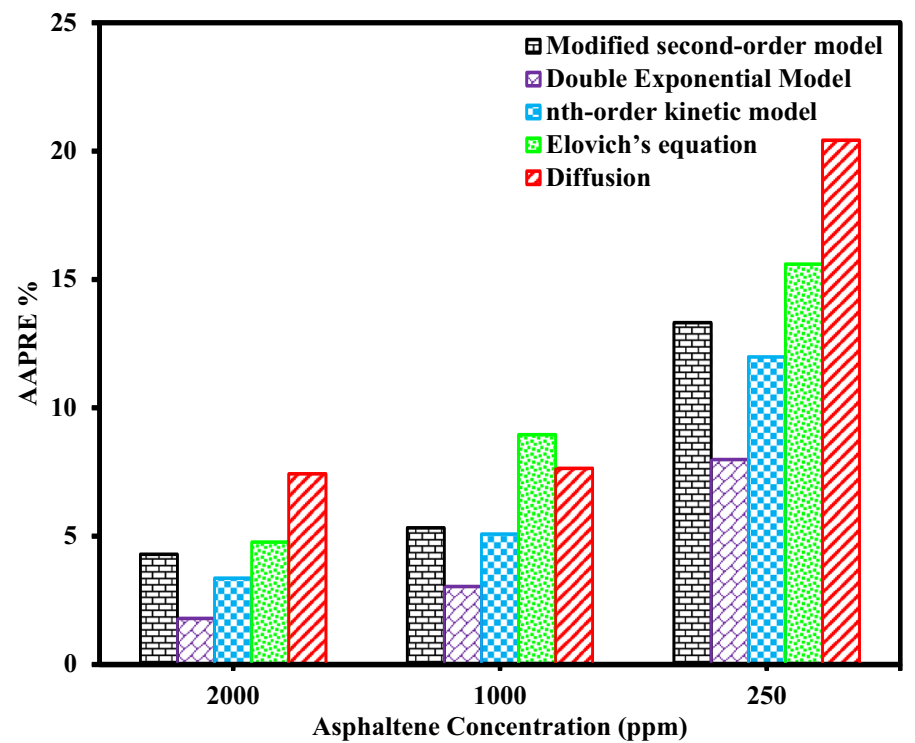

Figure 10. Comparison of deposition kinetics models at different asphaltene concentrations for PTFE coatings at dynamic state based on AAPRE.

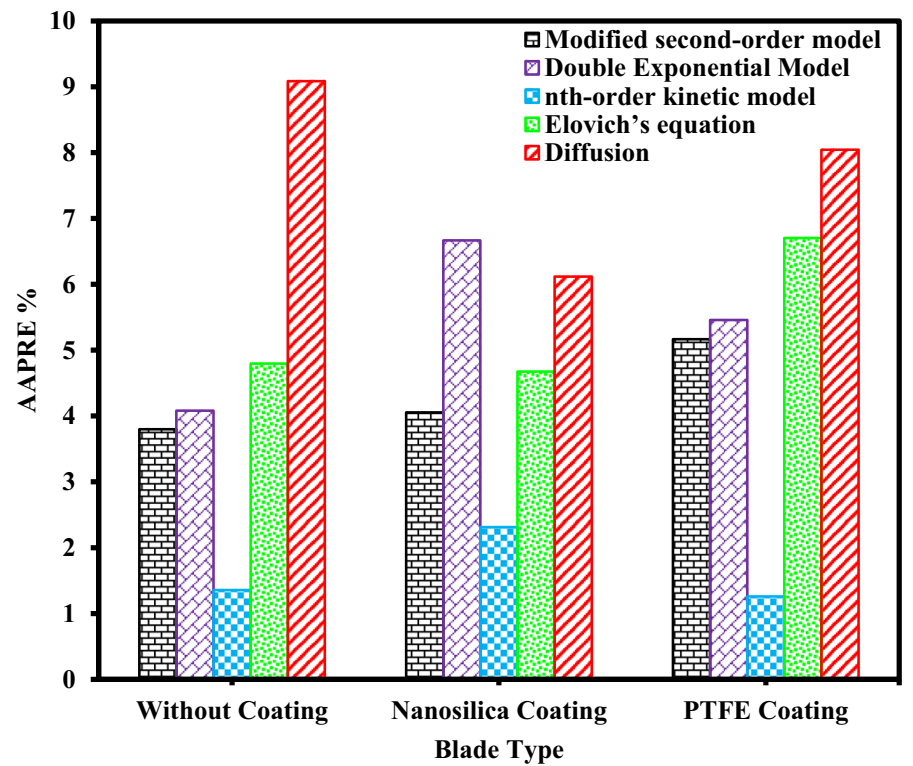

Figure 11. Comparison of deposition kinetics models for different coatings at concentration of $2000 \mathrm{ppm}$ in static state based on AAPRE.

In this study, the adsorption kinetic modeling showed that the initial deposition rate is faster than that at subsequent times. According to the literature, most unstable fractions of asphaltenes, which have a high metal content and are more polar, react to the electric field and form the first adsorbed layer on the electrode, which will lead to subsequent deposition ${ }^{69-71}$. Other studies have also shown that polar entities of asphaltene dominate the initial adsorption mechanism ${ }^{64,72-74}$. Therefore, it can be said that the first layer of asphaltene particles is bonded to the electrode surface under the influence of an electric field and starts a chemical reaction with it, but other particles are mainly affected by solvent interaction due to lack of direct contact with the electrode surface.

\section{Conclusions}

The application of internal coatings with low surface energy could help to tackle organic and inorganic scale depositions in pipes. Recent efforts have been devoted to producing coatings with special surface properties to prevent or minimize asphaltene deposition on metal srfaces. In this study, two superhydrophobic coatings, including PTFE and nanosilica coatings, were fabricated simply and practically, and their performance for 


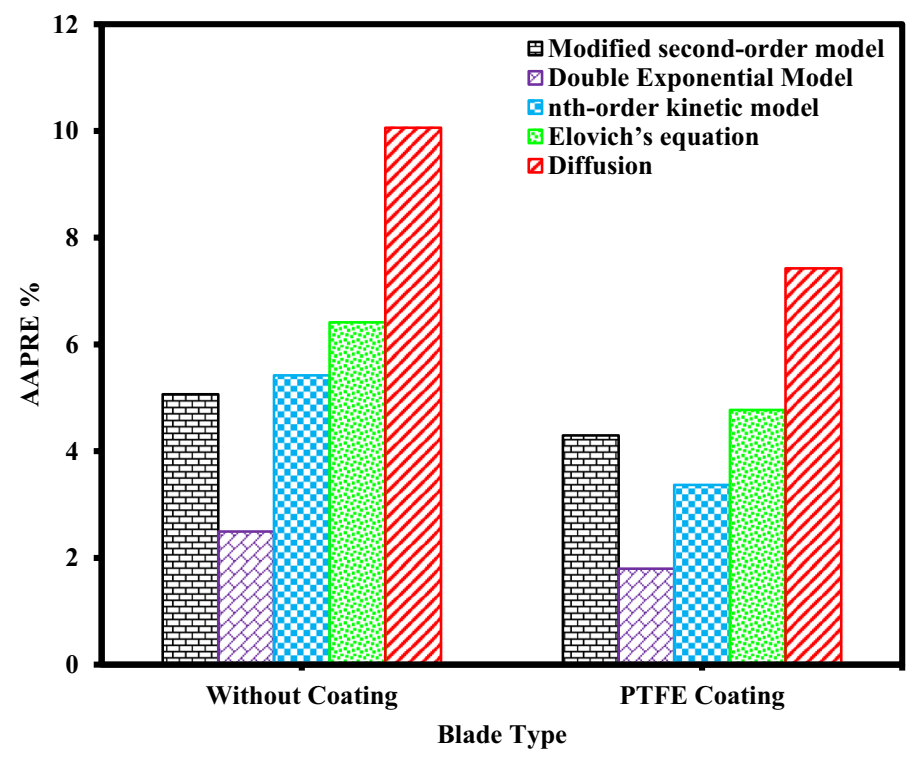

Figure 12. Comparison of deposition kinetics models for different coatings at concentration of $2000 \mathrm{ppm}$ in dynamic state based on AAPRE.

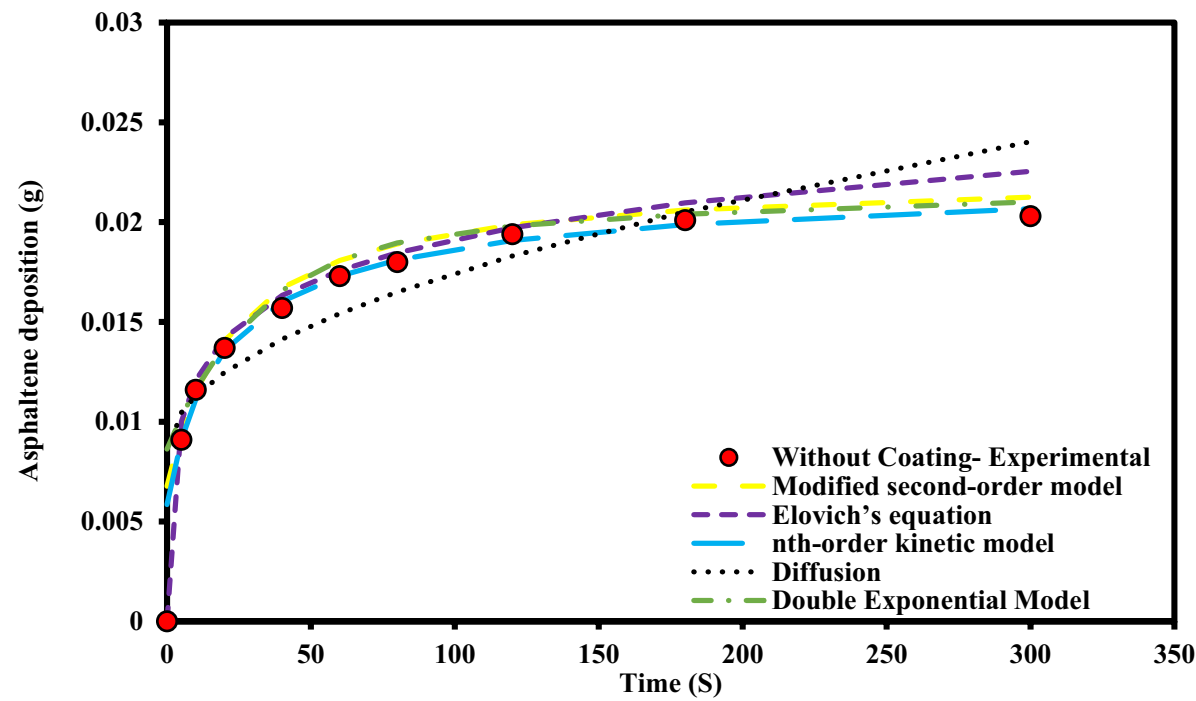

Figure 13. Comparison of experimental data and deposition kinetic models for uncoated electrode at 2000 ppm concentration in static state.

reducing asphaltene deposition was investigated. In this study, the effect of various factors including the type of coatings, fluid flow states, asphaltene concentration, and deposition time on the amount of asphaltene deposition was investigated and finally, the kinetics of asphaltene deposition in all these states were evaluated. We tried to show how the superhydrophobicity of a surface could increase its anti-scaling performance. Field application of this technique requires a comprehensive economic study based on net present value (NPV) analysis. This is an essential part of our future direction for extending the application of this technique in the field. The main findings of this study are as follows:

1. Surface wettability plays a major role in the amount of deposited asphaltene. Although both superhydrophobic coatings introduced in this study are capable of reducing the asphaltene deposits as compared to the uncoated electrode, the PTFE coating showed better performance.

2. At an asphaltene concentration of $2000 \mathrm{ppm}$ and compared to the uncoated electrode the PTFE coated electrode shows a $56 \%$ decrease in asphaltene depositions at static state and more than $70 \%$ decrease in the number of asphaltene depositions at dynamic state. 


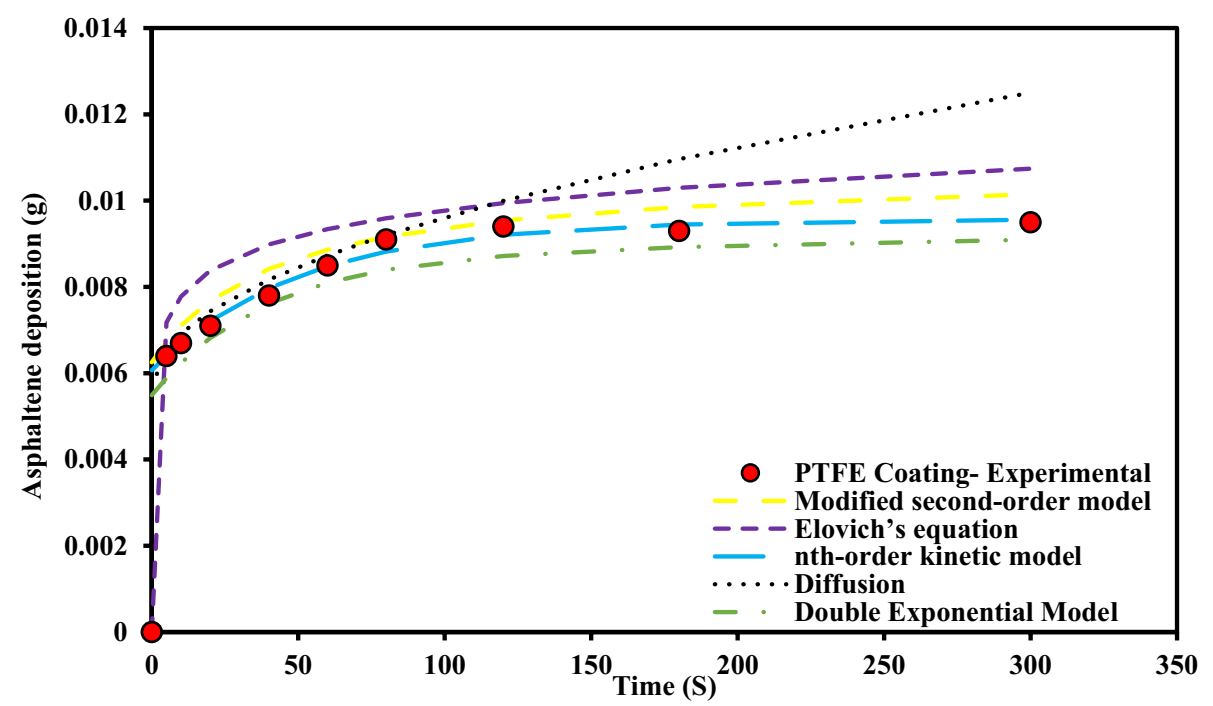

Figure 14. Comparison of experimental data and deposition kinetic models for PTFE coating electrode at 2000 ppm concentration in static state.

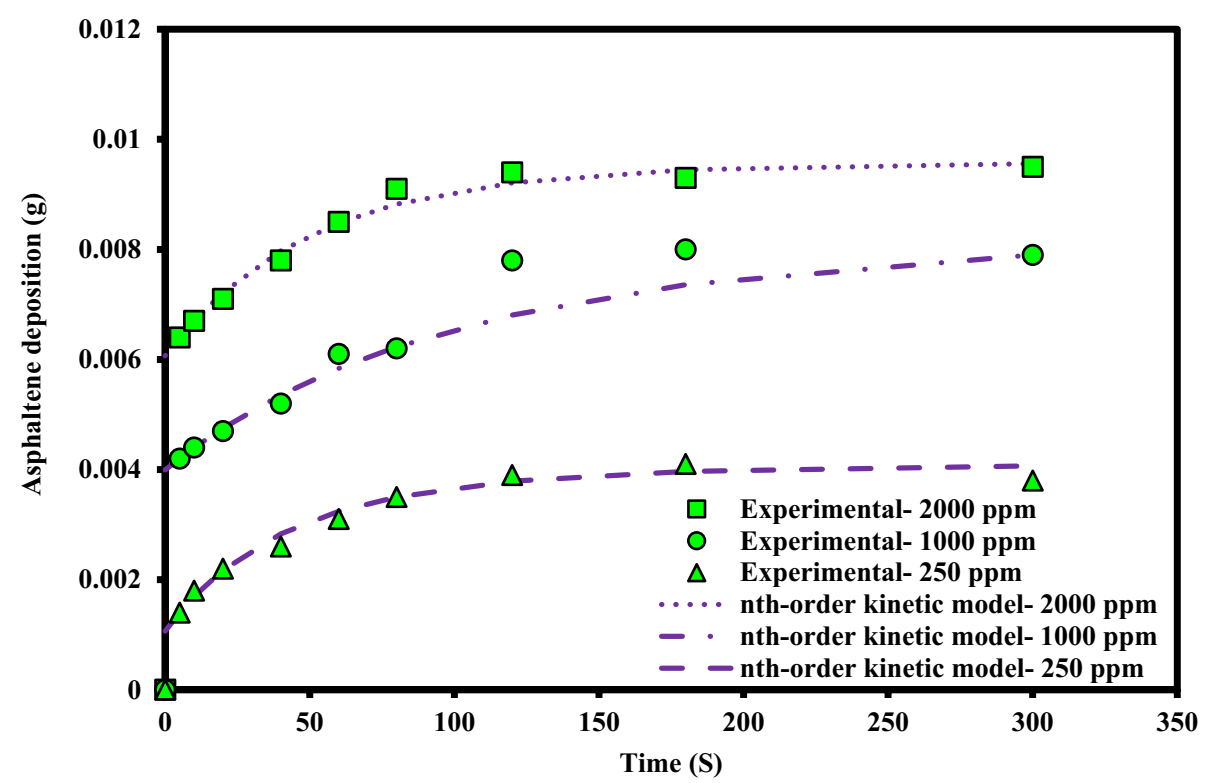

Figure 15. Agreement of the nth-Order deposition kinetic model to experimental data for different concentrations at static state for PTFE coating. 


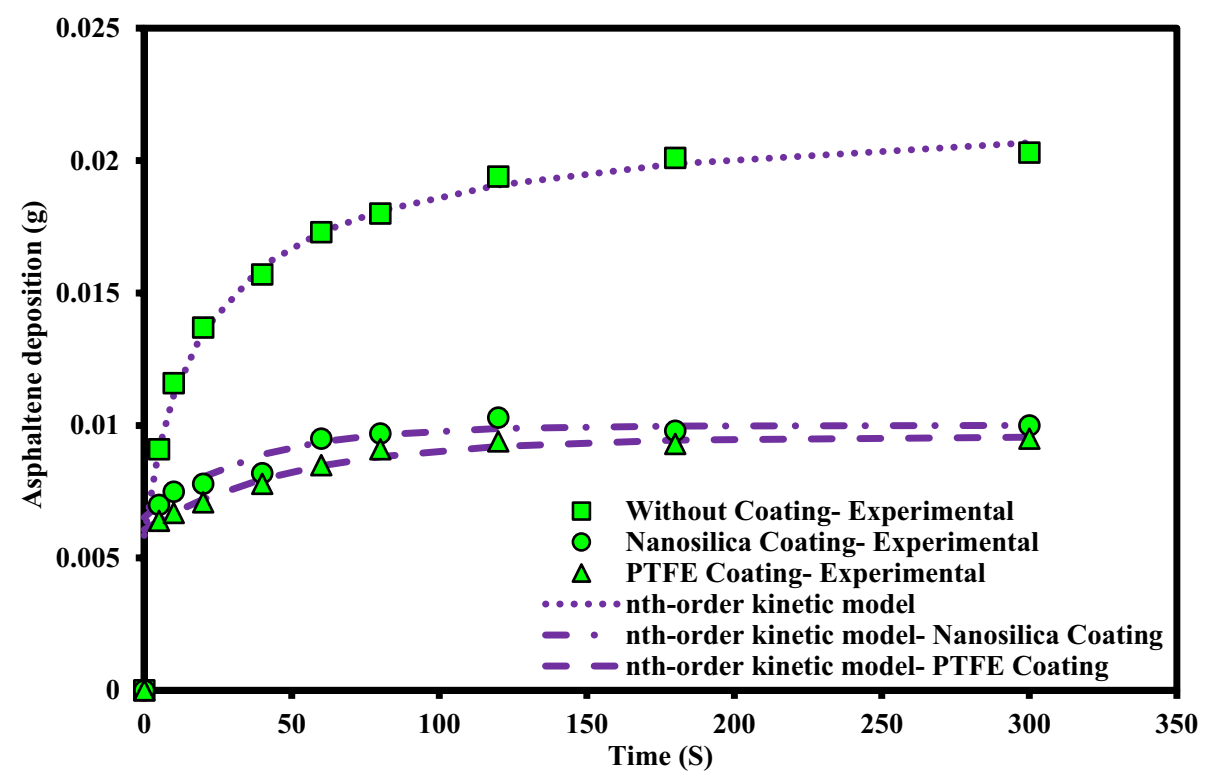

Figure 16. Agreement of the nth-Order deposition kinetic model to experimental data for different electrodes at static state.

3. The maximum amount of asphaltene deposition on the surface of the electrodes occurs during the first $120 \mathrm{~s}$ of the electrodeposition process.

4. The change of flow state affects the asphaltene deposition kinetics on the electrode surfaces. However, the type of electrode has no effect on the kinetics of asphaltene deposition. The results showed that the diffusion model and Elovich's equation are not in good agreement with the experimental data and the highest error is observed in these two ones. Investigation of the effect of flow type on the kinetics of asphaltene deposition showed that in the static state, the nth-order kinetics model, and in the dynamic state, the double exponential model has the best agreement with the experimental data. 


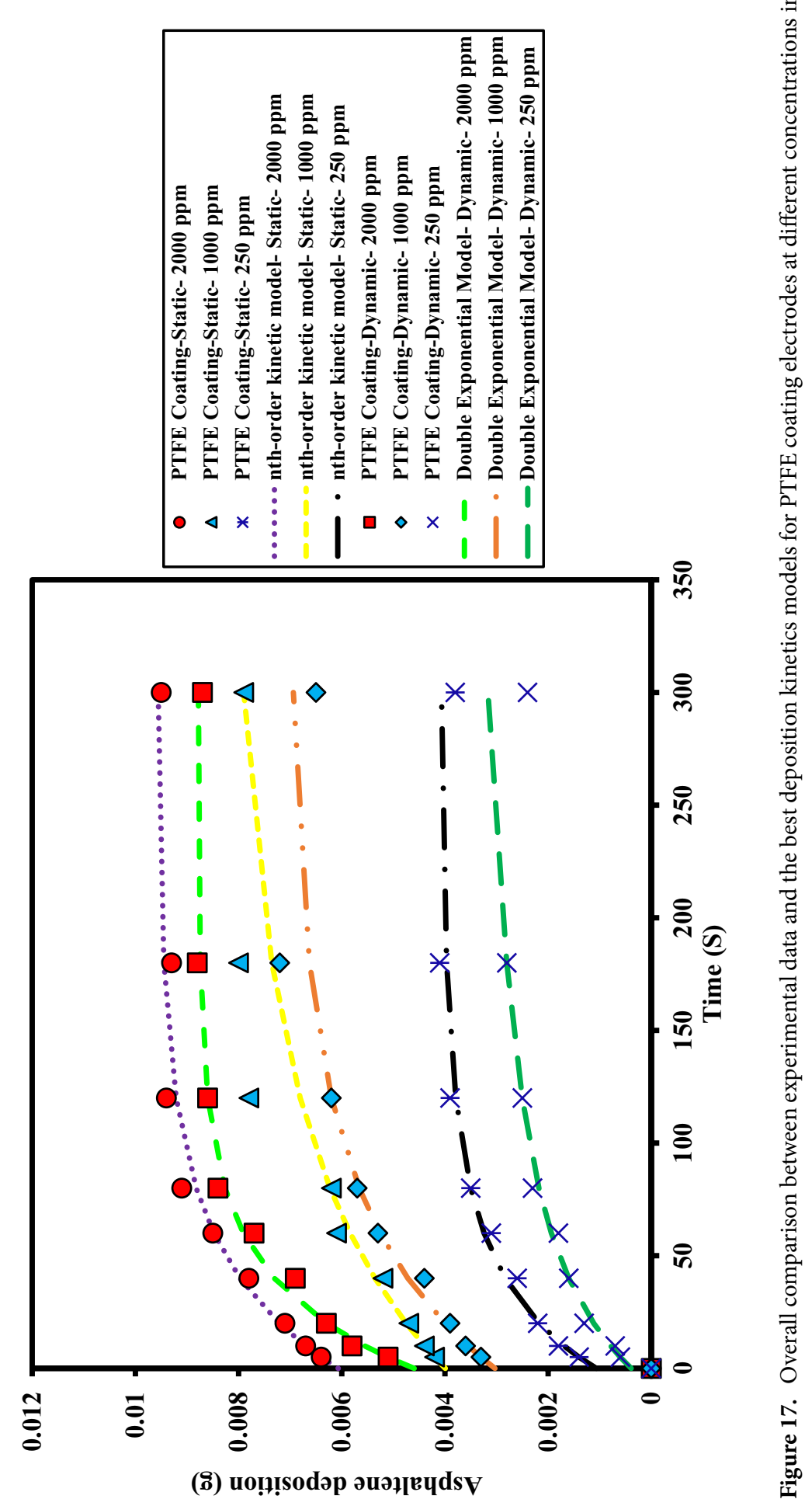


Received: 9 February 2021; Accepted: 22 July 2021

Published online: 19 August 2021

\section{References}

1. Moore, E., Crowe, C. \& Hendrickson, A. J. J. O. P. T. Formation, effect and prevention of asphaltene sludges during stimulation treatments. J. Pet. Technol. 17, 1023-021028 (1965).

2. Speight, J. J. O. Petroleum Asphaltenes-Part 1: Asphaltenes, resins and the structure of petroleum. Oil Gas Sci. Technol. 59, 467-477 (2004).

3. Escobedo, J. \& Mansoori, G. A. Asphaltene and other heavy-organic particle deposition during transfer and production operations. In SPE Annual Technical Conference and Exhibition. Society of Petroleum Engineers. (1995).

4. Davudov, D. \& Moghanloo, R. G. A new model for permeability impairment due to asphaltene deposition. Fuel 235, 239-248 (2019).

5. Buenrostro-Gonzalez, E., Lira-Galeana, C., Gil-Villegas, A. \& Wu, J. Asphaltene precipitation in crude oils: Theory and experiments. AIChE J. 50, 2552-2570 (2004).

6. Kord, S., Soleymanzadeh, A. \& Miri, R. A generalized scaling equation to predict asphaltene precipitation during precipitant dilution, natural depletion, water injection and gas injection. J. Pet. Sci. Eng. 182, 106320 (2019).

7. Mullins, O. C., Sheu, E. Y., Hammami, A. \& Marshall, A. G. Asphaltenes, Heavy Oils, and Petroleomics (Springer Science \& Business Media, 2007).

8. Wang, P. et al. Comparative analysis of $\mathrm{CO}_{2}, \mathrm{~N}_{2}$, and gas mixture injection on asphaltene deposition pressure in reservoir conditions. Energies 11, 2483 (2018).

9. Lobanov, A. et al. Prediction of asphaltenes deposition in the Russian oilfield: Laboratory investigations and modeling. J. Pet. Sci. Eng. 186, 106777 (2020).

10. Olkhovskaya, V., Struchkov, I. \& Evich, K. Estimation of field production profiles in case of asphaltene deposition. Resour. Eff. Technol. 2020(1), 16-31 (2020).

11. Groenzin, H. \& Mullins, O. C. Asphaltenes, Heavy Oils, and Petroleomics 17-62 (Springer, 2007).

12. Tavakkoli, M., Panuganti, S. R., Taghikhani, V., Pishvaie, M. R. \& Chapman, W. G. Asphaltene deposition in different depositing environments: Part 2. Real oil. Energy Fuels 28, 3594-3603 (2014).

13. Hammami, A. \& Ratulowski, J. Asphaltenes, Heavy Oils, and Petroleomics 617-660 (Springer, 2007).

14. Frenier, W. W. \& Ziauddin, M. A multifaceted approach for controlling complex deposits in oil and gas production. In SPE Annual Technical Conference and Exhibition. Society of Petroleum Engineers. (2010).

15. Mousavi, S.-P. et al. Toward mechanistic understanding of wettability alteration in calcite and dolomite rocks: The effects of resin, asphaltene, anionic surfactant, and hydrophilic nano particles. J. Mol. Liq. 321, 114672. https://doi.org/10.1016/j.molliq.2020. 114672 (2021).

16. Kord, S., Mohammadzadeh, O., Miri, R. \& Soulgani, B. S. Further investigation into the mechanisms of asphaltene deposition and permeability impairment in porous media using a modified analytical model. Fuel 117, 259-268 (2014).

17. Kuriakose, A. \& Manjooran, S. K. B. J. S. Bitumenous paints from refinery sludge. Surf. Coat. Technol. 145, 132-138 (2001).

18. Mansoori, G. A. \& Elmi, A. J. S. P. Remediation of asphaltene and other heavy organic deposits in oil wells and in pipelines. Socar Proc. 4, 12-23 (2010).

19. Shedid, S. A. \& Attallah, S. R. Influences of ultrasonic radiation on asphaltene behavior with and without solvent effects. In SPE International Symposium and Exhibition on Formation Damage Control. Society of Petroleum Engineers. (2004).

20. Zoveidavianpoor, M., Samsuri, A. \& Shadizadeh, S. J. E. S. The clean up of asphaltene deposits in oil wells. Energy Sources Part A Recovery Util. Environ. Effects 35, 22-31 (2013).

21. Bethke, G. K. et al. A novel coating to reduce solids deposition in production systems. In Offshore Technology Conference. Society of Petroleum Engineers. (2018).

22. Chi, Y., Daraboina, N. \& Sarica, C. Investigation of inhibitors efficacy in wax deposition mitigation using a laboratory scale flow loop. AIChE J. 62, 4131-4139 (2016).

23. Kumar, D., Chishti, S. S., Rai, A. \& Patwardhan, S. D. Scale inhibition using nano-silica particles. In SPE Middle East Health, Safety, Security, and Environment Conference and Exhibition. Society of Petroleum Engineers. (2012).

24. McKeen, L. W., Mohan, P. K., Mestemacher, S. A., Farnsworth, K. D. \& Obal, W. D. Coated pipes for harsh environments. U.S. Patent. (2011).

25. Rashidi, M., Mombekov, B. \& Marhamati, M. A study of a novel inter pipe coating material for paraffin wax deposition control and comparison of the results with current mitigation technique in oil and gas industry. In Offshore Technology Conference Asia. Society of Petroleum Engineers. (2016).

26. Vázquez-Noriega, O. E. et al. Recent Insights in Petroleum Science and Engineering (IntechOpen, 2017).

27. Wei, R., Johnson, R. L., Rincon, C. \& Miller, M. A. Method for plasma immersion ion processing and depositing coatings in hollow substrates using a heated center electrode. U.S. Patent. (2014).

28. Frenier, W. W. \& Ziauddin, M. Formation, Removal, and Inhibition of Inorganic Scale in the Oilfield Environment (Society of Petroleum Engineers Richardson, 2008).

29. Liu, Y., Zhuge, X., Wang, Z., Huang, B. \& Le, X. Case Study on Fluorocarbons Interior Coating for Anticorrosion and Wax-Deposition Inhibition in ASP Flooding Production. In SPE Annual Technical Conference and Exhibition. Society of PetroleumEngineers. (2018).

30. Joonaki, E., Buckman, J., Burgass, R. \& Tohidi, B. J. S. R. Water versus asphaltenes; liquid-liquid and solid-liquid molecular interactions unravel the mechanisms behind an improved oil recovery methodology. Sci. Rep. 9, 1-13 (2019).

31. Hemmati-Sarapardeh, A., Dabir, B., Ahmadi, M., Mohammadi, A. H. \& Husein, M. M. Toward mechanistic understanding of asphaltene aggregation behavior in toluene: The roles of asphaltene structure, aging time, temperature, and ultrasonic radiation. J. Mol. Liq. 264, 410-424 (2018).

32. Ahooei, A., Norouzi-Apourvari, S., Hemmati-Sarapardeh, A. \& Schaffie, M. Experimental study and modeling of asphaltene deposition on metal surfaces via electrodeposition process: The role of ultrasonic radiation, asphaltene concentration and structure. $J$. Pet. Sci. Eng. 195, 107734 (2020).

33. Goual, L., Horváth-Szabó, G., Masliyah, J. H. \& Xu, Z. Characterization of the charge carriers in bitumen. Energy Fuels 20, 2099-2108 (2006).

34. Khvostichenko, D. S. \& Andersen, S. I. Electrodeposition of asphaltenes. 1. Preliminary studies on electrodeposition from oilheptane mixtures. Energy Fuels 23, 811-819 (2009).

35. Taylor, S. E. The electrodeposition of asphaltenes and implications for asphaltene structure and stability in crude and residual oils. Fuel 77, 821-828 (1998).

36. Zekri, A. Y., Shedid, S. A. \& Alkashef, H. A new technique for treatment of permeability damage due to asphaltene deposition using laser technology. J. Pet. Sci. Eng. 59, 300-308 (2007).

37. Asaadian, H., Soltani Soulgani, B. \& Karimi, A. An experimental study on electrical effect on asphaltene deposition. Pet. Sci. Technol. 35, 2255-2261 (2017). 
38. Taghavi, H., Ashoori, S. \& Mousavi, S. H. Analyzing electrical field effect on asphaltene deposition. Pet. Sci. Technol. 36, 487-493 (2018).

39. Hosseini, A. et al. Electrokinetic behavior of asphaltene particles. Fuel 178, 234-242 (2016).

40. Chauveteau, G., Nabzar, L. \& Coste, J. Physics and modeling of permeability damage induced by particle deposition. In SPE Formation Damage Control Conference. Society of Petroleum Engineers. (1998).

41. Kurup, A. S., Buckley, J. S., Wang, J., Subramani, H. J., Creek, J. L., \& Chapman, W. G. Asphaltene deposition tool: Field case application protocol. In Offshore Technology Conference. Society of Petroleum Engineers. (2012).

42. Nabzar, L. \& Aguiléra, M. The colloidal approach. A promising route for asphaltene deposition modelling. . Oil Gas Sci. Technol. Revue de l'IFP 63, 21-35 (2008).

43. Rastegari, K., Svrcek, W. Y. \& Yarranton, H. W. Kinetics of asphaltene flocculation. Ind. Eng. Chem. Res. 43, 6861-6870 (2004).

44. Abutaqiya, M. I., Sisco, C. J., Wang, J. \& Vargas, F. M. Systematic investigation of asphaltene deposition in the wellbore and near-wellbore region of a deepwater oil reservoir under gas injection. Part 1: thermodynamic modeling of the phase behavior of polydisperse asphaltenes. Energy Fuels 33, 3632-3644 (2019).

45. Taherpour, A., Cheshmeh Sefidi, A., Bemani, A. \& Hamule, T. Application of Fuzzy c-means algorithm for the estimation of Asphaltene precipitation. Pet. Sci. Technol. 36, 239-243 (2018).

46. Wilczak, A. \& Keinath, T. M. Kinetics of sorption and desorption of copper (II) and lead (II) on activated carbon. Water Environ. Res. 65, 238-244 (1993).

47. Shayan, N. N. \& Mirzayi, B. Adsorption and removal of asphaltene using synthesized maghemite and hematite nanoparticles. Energy Fuels 29, 1397-1406 (2015).

48. Gupta, S. S. \& Bhattacharyya, K. G. Kinetics of adsorption of metal ions on inorganic materials: A review. Adv. Coll. Interface. Sci. 162, 39-58 (2011).

49. Qiu, H. et al. Critical review in adsorption kinetic models. J. Zhejiang Univ. Sci. A 10, 716-724 (2009).

50. Tosun, İ. Ammonium removal from aqueous solutions by clinoptilolite: Determination of isotherm and thermodynamic parameters and comparison of kinetics by the double exponential model and conventional kinetic models. Int. J. Environ. Res. Public Health 9, 970-984 (2012).

51. Andersen, S. I. \& Christensen, S. D. The critical micelle concentration of asphaltenes as measured by calorimetry. Energy Fuels 14, $38-42(2000)$.

52. Standal, S., Haavik, J., Blokhus, A. \& Skauge, A. Effect of polar organic components on wettability as studied by adsorption and contact angles. J. Pet. Sci. Eng. 24, 131-144 (1999).

53. Liu, L. \& Buckley, J. S. Alteration of wetting of mica surfaces. J. Pet. Sci. Eng. 24, 75-83 (1999).

54. Chang, J. H. \& Hunter, I. W. Characterization and control of the wettability of conducting polymer thin films. MRS Online Proceedings Library Archive. 1228 (2009).

55. Lauer, R. S. The use of high performance polymeric coatings to mitigate corrosion and deposit formation in pipeline applications. In CORROSION 2007. Society of Petroleum Engineers. (2007).

56. Owens, D. K. \& Wendt, R. Estimation of the surface free energy of polymers. J. Appl. Polym. Sci. 13, 1741-1747 (1969).

57. Sedlmeier, F. et al. Water at polar and nonpolar solid walls. Biointerphases 3, FC23-FC39 (2008).

58. Skartlien, R., Simon, S. \& Sjöblom, J. DPD molecular simulations of asphaltene adsorption on hydrophilic substrates: Effects of polar groups and solubility. J. Dispers. Sci. Technol. 37, 866-883 (2016).

59. Jestin, J., Simon, S., Zupancic, L. \& Barré, L. A small angle neutron scattering study of the adsorbed asphaltene layer in water-inhydrocarbon emulsions: Structural description related to stability. Langmuir 23, 10471-10478 (2007).

60. Wang, S., Liu, J., Zhang, L., Xu, Z. \& Masliyah, J. Colloidal interactions between asphaltene surfaces in toluene. Energy Fuels 23, 862-869 (2009).

61. Adams, J. J. Asphaltene adsorption, a literature review. Energy Fuels 28, 2831-2856 (2014).

62. Abdallah, W. A. \& Taylor, S. D. Study of asphaltenes adsorption on metallic surface using XPS and TOF-SIMS. J. Phys. Chem. C 112, 18963-18972 (2008).

63. Dudášová, D., Simon, S., Hemmingsen, P. V. \& Sjöblom, J. Study of asphaltenes adsorption onto different minerals and clays: Part 1. Experimental adsorption with UV depletion detection. Colloids Surf. A Physicochem. Eng. Aspects 317, 1-9 (2008).

64. Jouault, N., Corvis, Y., Cousin, F., Jestin, J. \& Barré, L. C. Asphaltene adsorption mechanisms on the local scale probed by neutron reflectivity: Transition from monolayer to multilayer growth above the flocculation threshold. Langmuir 25, 3991-3998 (2009).

65. Moradi, S., Amirjahadi, S., Danaee, I. \& Soltani, B. Experimental investigation on application of industrial coatings for prevention of asphaltene deposition in the well-string. J. Pet. Sci. Eng. 181, 106095 (2019).

66. Seyedmehdi, S. A., Zhang, H. \& Zhu, J. Superhydrophobic RTV silicone rubber insulator coatings. Appl. Surf. Sci. 258, 2972-2976 (2012).

67. Wang, Y. et al. Enhanced performance of superhydrophobic polypropylene membrane with modified antifouling surface for high salinity water treatment. Sep. Purif. Technol. 214, 11-20 (2019).

68. Tavakkoli, M. et al. Asphaltene deposition in different depositing environments: Part 1. Model oil. Energy Fuels 28, 1617-1628 (2014).

69. Cosultchi, A., Rossbach, P. \& Hernández-Calderon, I. XPS analysis of petroleum well tubing adherence. Surf. Interface Anal. 35, 239-245 (2003).

70. Maqbool, T., Balgoa, A. T. \& Fogler, H. S. Revisiting asphaltene precipitation from crude oils: A case of neglected kinetic effects. Energy Fuels 23, 3681-3686 (2009).

71. Wattana, P., Fogler, H. S., Yen, A., Carmen Garcì, M. D. \& Carbognani, L. Characterization of polarity-based asphaltene subfractions. Energy Fuels 19, 101-110 (2005).

72. Abudu, A. \& Goual, L. Adsorption of crude oil on surfaces using quartz crystal microbalance with dissipation (QCM-D) under flow conditions. Energy Fuels 23, 1237-1248 (2009).

73. Turgman-Cohen, S., Smith, M. B., Fischer, D. A., Kilpatrick, P. K. \& Genzer, J. Asphaltene adsorption onto self-assembled monolayers of mixed aromatic and aliphatic trichlorosilanes. Langmuir 25, 6260-6269 (2009).

74. Xing, C., Hilts, R. \& Shaw, J. M. Sorption of Athabasca vacuum residue constituents on synthetic mineral and process equipment surfaces from mixtures with pentane. Energy Fuels 24, 2500-2513 (2010).

\section{Author contributions}

M.H.S.: Investigation, formal analysis, data curation, visualization, writing-original draft, S.N.-A.: Conceptualization, supervision, writing-review \& editing, A.I.: Supervision, validation, A.H.-S.: Methodology, validation, writing-review \& editing, M.S.: Writing-review \& editing, A.M.: Validation, writing-review \& editing, funding.

\section{Competing interests}

The authors declare no competing interests. 


\section{Additional information}

Supplementary Information The online version contains supplementary material available at https:/doi.org/ 10.1038/s41598-021-95657-5.

Correspondence and requests for materials should be addressed to S.N.-A., A.H.-S. or A.M.

Reprints and permissions information is available at www.nature.com/reprints.

Publisher's note Springer Nature remains neutral with regard to jurisdictional claims in published maps and institutional affiliations.

(c) (i) Open Access This article is licensed under a Creative Commons Attribution 4.0 International License, which permits use, sharing, adaptation, distribution and reproduction in any medium or format, as long as you give appropriate credit to the original author(s) and the source, provide a link to the Creative Commons licence, and indicate if changes were made. The images or other third party material in this article are included in the article's Creative Commons licence, unless indicated otherwise in a credit line to the material. If material is not included in the article's Creative Commons licence and your intended use is not permitted by statutory regulation or exceeds the permitted use, you will need to obtain permission directly from the copyright holder. To view a copy of this licence, visit http://creativecommons.org/licenses/by/4.0/.

(C) The Author(s) 2021 